ANUARIO DE Estudios MEDIEVALES

43/2, julio-diciembre de 2013, pp. 871-914

ISSN 0066-5061

doi:10.3989/aem.2013.43.2.13

\title{
ARTE Y TECNOLOGÍA TEXTIL: EL EMBLEMA DE SANTIAGO EL MENOR (SIGLOS XI-XVI)'
}

\author{
ART AND TEXTILE TECHNOLOGY: \\ THE ATTRIBUTE OF ST JAMES THE LESS (11th-16th CENTURIES)
}

\author{
ALEXANDRA USCATESCU \\ Universidad Complutense de Madrid
}

\begin{abstract}
Resumen: La imagen del apóstol Santiago el Menor constituye un buen ejemplo que permite analizar los distintos avatares que provocaron cambios iconográficos en el emblema del martirio del apóstol, desde el siglo XI y hasta el XVI en Europa occidental, relacionados a su vez con ciertas innovaciones técnicas de los instrumentos de trabajo del oficio textil, así como con factores de carácter léxico, social y psicológico.
\end{abstract}

Palabras clave: iconografía medieval; Santiago el Menor; pertica fullonis; arco de lana o algodón.

\begin{abstract}
The image of Saint James the Less constitutes a good example of how technological changes can determine iconographic transformations. Therefore, this paper will focus on some morphological changes observed in the apostle's attribute, from the 11th to the $16^{\text {th }}$ century in Western Europe, which are related to certain technical improvements in the textile trade, as well as to some lexical, social and psychological factors.
\end{abstract}

Keywords: medieval iconography; Saint James the Less; pertica fullonis; wool or cotton bow.

\section{SUMARIO}

1. Introducción.- 2. El relato del martirio de Santiago el Menor.- 3. Léxico versus imagen: factores psicológicos y léxicos del cambio iconográfico.- 4. Un cambio inesperado: el arcvs cvthonis.- 5. El nuevo atributo como generador de confusión: la sierra y la escuadra.- 6. Un equívoco: el juego convertido en labor.- 7. A modo de conclusión.- 8. Bibliografía citada.

${ }^{1}$ Este artículo forma parte de los resultados del proyecto de investigación HAR2009-08901 del Ministerio de Ciencia e Innovación. Abreviaturas utilizadas: $\mathrm{BHG}=$ Bibliotheca Hagiographica Graeca; $\mathrm{BHL}=$ Bibliotheca Hagiographica Latina Antiqua et Mediae Aetatis; CC = Corpus Christianorum; $\mathrm{CCCM}=$ Corpus Christianorum Continuatio Mediaevalis; $\mathrm{CSCO}=$ Corpus Scriptorum Christianorum Orientalium; MGH = Monumenta Germaniae Historica; $\mathrm{PL}=$ Patrologia Latina; RAE = Real Academia Española $; \mathrm{TLF}=$ Trésor de la Langue Française. 


\section{INTRODUCCIÓN}

El sistema de caracterización iconográfica de los personajes cristianos suele destacar por una relativa estabilidad formal basada en la coherencia, más o menos fiel, con respecto a la tradición narrativa hagiográfica vigente en el momento histórico en el que se enmarca la producción artística en cuestión. En ocasiones, la variabilidad regional y cronológica de la cultura visual pre-tridentina puede llegar a sorprender por su creatividad o su capacidad de recrear una cultura material obliterada por la industrialización de la producción artesanal de los últimos siglos. La representación del martirio del apóstol Santiago el Menor es uno de esos casos en los que el diseño del arma de martirio se convierte en un reflejo de la tecnología textil y de la sociedad de su época. En este sentido, el presente estudio pretende indagar en los factores artísticos, léxicos, psicológicos o técnicos que han regido la creación artística relacionada con la imaginería de ese santo ${ }^{2}$.

La importancia de Santiago el Menor en la tradición artística occidental explica por sí sola su presencia en los principales manuales iconográficos, a los que remito al lector interesado en un corpus exhaustivo de obras en las que aparece el apóstol ${ }^{3}$, ya que el objetivo de este trabajo no es engrosar dicho listado, sino profundizar en los factores antes mencionados, así como en posibles acotaciones regionales y cronológicas en el contexto del arte occidental pre-tridentino (siglos XI-XVI). Entre todas esas obras ocupa un lugar destacado el ya centenario opusculum de Bedford que constituye el estudio más completo editado hasta la fecha sobre la iconografía de este apóstol ${ }^{4}$. El resto de los estudios iconográficos suele aceptar la interpretación tradicional, sin cuestionar la adecuación del atributo adjudicado al trabajo que supuestamente se efectuaba con éste: asumen, sin asomo de duda, que se trata de un retrato fiel del instrumento de trabajo mencionado en las fuentes literarias. Es, por otra parte, comprensible que los compendios iconográficos cristianos clásicos -obras de Réau, Cahier o Böhm- no puedan atender por igual cada uno de los aspectos que abarca la iconografía y mucho menos profundizar en todos los pormenores tecnológicos de carácter más interdisciplinar.

${ }^{2}$ Quisiera agradecer todo el apoyo bibliográfico recibido por parte del Dr. J. Uscatescu, de la Universidad de Friburgo. Y tampoco puedo dejar pasar la ocasión de agradecer al Prof. Dr. J. Martínez de Aguirre de la Universidad Complutense de Madrid las observaciones realizadas al manuscrito original.

${ }_{3}^{3}$ B. Böhm, Jakobus, cols. 47-51; C. Cahier, Caracteristiques, p. 831; R. Plotino, Giacomo, cols. 401-410; L. Réau, Iconographie, pp. 703-704; E. Ricci, Mille, p. 67.

${ }^{4}$ La obra de Bedford contiene algunas atribuciones que se han revelado erróneas, como se verá a lo largo del texto, pero que no restan ni un ápice a su interés e importancia como primera monografía artística sobre Santiago el Menor (véase: R.P. Bedford, Saint James). 


\section{El RELATO DEL MARTIRIO DE SANTIAGO EL MENOR}

En la figura de Santiago confluyen diversas transmisiones literarias. En la tradición medieval se le aplica el sobrenombre de minor para diferenciarlo de Santiago, el hijo de Zebedeo, pero también puede aparecer calificado como frater Domini ${ }^{5}$, un parentesco que termina aclarándose como "primo" de Jesús puesto que, mediante el popular trinubium de Santa Ana, se establece que la Virgen era hermanastra de la esposa de Cleofás, padre de Santiago el Menor. En otras ocasiones, se señala que éste es hijo de Alfeo (según la tradición occidental, Cleofás y Alfeo son la misma persona) y ésta es la identidad que queda fijada en el Concilio de Trento (1545-1563). Las narraciones orientales, en cambio, distinguen entre Santiago, el obispo de Jerusalén, y el apóstol al que consideran hijo de Alfeo. Una distinción que pudo haberse introducido, a finales del siglo II, y que será la que siga Eusebio de Cesarea en su Historia Eclesiástica, cuya versión es una de las piedras angulares para la fijación y transmisión del relato hagiográfico de Santiago.

La narración de su martirio es algo menos confusa y procede de una tradición derivada de círculos judeo-cristianos de época romana, recogida en los escritos pseudo-clementinos (Recognitiones), en la traducción de Rufino de Aquilea del texto de Hegesipo y en el apócrifo del Pseudo-Abdías, de finales del siglo VI o VII, traducido al griego y posteriormente al latín (Historia Certaminis Apostolici o Historiae Apostolicae $)^{6}$. Los datos cronológicos que permiten situarlo en el año 62 se deben a Flavio Josefo, quien, en sus Antigüedades Judías, indica que Santiago, el "hermano de Jesús", fue condenado a la lapidación ${ }^{7}$. Son pocos los que albergan dudas de que se trate de una interpolación cristiana posterior ${ }^{8}$. A inicios del siglo IV, Eusebio (BHG 765h) se hace eco de un testimonio anterior, de finales del siglo II o inicios de la centuria siguiente, que señala que el santo fue golpeado con un madero hasta morir'. A continuación, Eusebio cita la relación de Hegesipo contenida en las memorias de éste redactadas a finales del siglo II, una narración que se convertirá en la base del resto de leyendas hagiográficas sobre Santiago a las que únicamente se le añaden un mayor número de milagros ${ }^{10}$ : Santiago, tras haber sido

${ }^{5}$ Mateo, 13, 55; Marcos, 6, 3; Gálatas, 1, 19.

${ }^{6}$ A. de Santos, Later, p. 478.

${ }^{7}$ L.H. Feldman, Josephus, 20, 201.

${ }^{8}$ Ibidem, p. 496 y nota c.

9 F. Halkin, Auctarium; F, Halkin, Nouum auctarium.

${ }^{10}$ L. Leloir, Écrits, pp. 478, 680 y 740. Por otro lado, existe otra tradición transmitida por Nicetas de Paflagonia, de finales del siglo IX e inicios del X, que señala que Santiago, hijo de Alfeo, fue crucificado (F. Bovon, Byzantine, p. 93). 
arrojado de la cima del templo, fue golpeado en la cabeza por un batanero con un madero, produciéndole la muerte ${ }^{11}$. Esta versión es la que traduce Rufino al latín (BHL 4086), a finales del siglo IV, y la que transmite Jerónimo en la misma época (BHL 4087) y los Hechos apócrifos de los apóstoles (BHL 4088), constituyendo la base de la pasión latina del Pseudo-Abdías (BHL 4089).

El hecho de que el arma de la pasión de Santiago fuese empuñada por un batanero ha sido determinante en la configuración iconográfica de su martirio, aunque las representaciones artísticas no siempre muestren un conocimiento preciso de la ars fullonia, un oficio que se desarrolla desde la Antigüedad con pocos cambios y que implicaba el tratamiento de la lana, y particularmente su acabado para convertir los tejidos en paños aptos para combatir las inclemencias de tiempo. En el Medievo, se mantiene la misma tecnología con algunas innovaciones (p.e.: batanes hidráulicos). En época romana, la denominación de fullo designa a todo el oficio que comprendía distintas labores específicas: cardado de paños, enfurtido, estirado, tundido y prensado ${ }^{12}$. Con el tiempo, el panorama se complica, y a lo largo de la Edad Media surgen distintas denominaciones para cada uno de esos estadios o especialidades del trabajo textil: batanero, tundidor, cardador, etc. que obviamente no reflejan los textos literarios referidos al martirio de Santiago, ya que siempre mantienen al batanero como verdugo del santo. Esos cambios solo se manifiestan en la iconografía del santo pues el arma del martirio sí cambia.

La reconstrucción arqueológica de la pasión de Santiago no es empresa fácil, pues ésta se desarrolló en lo que actualmente se conoce como explanada de las mezquitas, en una zona en cuyo subsuelo prácticamente no se han podido realizar indagaciones ${ }^{13}$. El relato muestra las características propias del género literario, aunque presenta rasgos que le confieren verosimilitud. En primer lugar, el apóstol es arrojado del tejado del templo (gr. pterýgion; lat. pinna templi, tectus templi) por lo que la escena se habría desarrollado al aire libre, lo cual concuerda con que entre su auditorio hubiera gentiles, pues el interior del templo les estaba vedado ${ }^{14}$. El hecho de llevar en recinto sagrado un instrumento de trabajo que virtualmente se puede convertir

11 En Santiago de Compostela, se conserva un cráneo roto en su parte superior que forma parte de un busto relicario atribuido al orfebre Eans, siendo posterior a 1330 (J.M. García, Santiagos, p. 179 y nota 23 en p. 188).

${ }_{12}$ H. Blümner, Technologie, pp. 170-190; R.J. Forbes, Studies, pp. 82-90 y 93-96; A. Uscatescu, Fullonicae, pp. 43-45.

${ }^{13}$ Los escasas intervenciones arqueológicas aparecen resumidas en: D. Bahat, Jerusalem, p. 232.

${ }^{14} \mathrm{H}$. Leclerq, Jacques le mineur, col. 2110. 
en un arma atenta contra la legislación judía ${ }^{15}$, pero cumple su papel dramático al añadir vileza al verdugo. Por otro lado, dentro de la cultura romana los fullones, especialmente en la comedia togata y atellana ${ }^{16}$, habían sido objeto de mofa por su vinculación con sustancias como la orina, los colorantes o su continuo saltar en la pila para enfurtir los $\operatorname{paños}^{17}$, y no hay que olvidar que, si bien esos relatos se generan entre círculos judeo-cristianos, su imaginario popular no era distinto al resto de la población romanizada del Imperio. Por desgracia, no hay datos sobre la ubicación exacta de las fullonicae en la topografía de la Jerusalén. Los datos que tenemos son muy anteriores, de época del rey Ezequías, e indican que los bataneros se debían situar en la parte baja de la ciudad, en la llamada "Ciudad de David", a los pies del Ofel, al sur de la colina del Templo, en el lugar conocido como "Campo del batanero" (el ager fullonis de la Vulgata) ${ }^{18}$, donde se encuentra un acueducto subterráneo de esa misma época (fin siglo VIII a.C. ${ }^{19}$. La disponibilidad de agua es uno de los requisitos para el batán -incluso antes de la introducción de la fuerza hidráulica- ${ }^{20}$ por lo que se puede especular con una ubicación similar para los fullones coetáneos a Santiago el Menor, extremo que vendría avalado por el comentario del Onomastikon de Eusebio, traducido por Jerónimo, quien señala que el ager fullonis se situaba entonces en un suburbio de Jerusalén ${ }^{21}$. La zona cercana a la colina del Templo cuenta con otras instalaciones de artesanado vinculado, pues en el Ofel hay restos de una tintorería de época tardoantigua (siglos V-VI) ${ }^{22}$.

El léxico griego empleado por el relato más extenso, el de Hegesipo (BHG 765h), es bastante impreciso en cuanto al instrumento de martirio, pues indica escuetamente que se trata de un madero (tó xýlon), un término ambiguo, pero que no suele emplearse para la madera viva, sino para la trabajada. Lo genérico de la denominación queda patente a continuación, pues el texto tiene

${ }^{15}$ La zona al sur del muro meridional está plagada de baños rituales que dan una idea de la ingente "necesidad de preservar las leyes de pureza en el templo" (D. Bahat, Jerusalem, p. 233). Además, la ley judía establece que ciertas industrias nocivas por olores y sustancias empleados queden separadas de la población (I.M. Ha-Kohen, Mishpat 155, 22-23).

16 A. Pociña, Recursos, p. 244.

${ }_{17}$ El famoso saltus fullonius de Séneca (E. N., Gardiner, Further, pp. 179-180).

${ }_{18}$ Isaías 7,3; 36,2; 2 Reyes 18,17.

19 J.C.H. Laughlin, Archaeology, pp. 145-146.

${ }^{20}$ Los primeros batanes movidos por fuerza hidráulica se atestiguan en Italia, en Abruzo (962), Parma (973), en las orillas del Serchio en Toscana (983), Verona (985) o Lodi (1008), Argentan en Normandía (1086), Grenoble (1040) y en España el molendino drapario de Salt en Gerona (1166), por citar algún ejemplo (E. Crowfoot, F. Pritchard, K. Staniland, Textile, p. 17; J.H. Munro, Medieval, p. 204). Más recientemente, se ha analizado el caso del Guadalquivir (véase: R. Córdoba, Los batanes, pp. 593-622).

${ }^{21}$ Onomastikon, 13, 1 (véase: F. Larsow, G. Parthey, Eusebii).

22 B. Mazar, The Archaeological, p. 38; J.S. Crawford, The Byzantine, pp. 121-122. 
que aclarar que se trata del madero con el que el batanero golpea los paños, y esta aclaración es la que puede arrojar luz sobre la morfología real de ese objeto.

La traducción de Rufino influye determinantemente en la totalidad de la transmisión literaria occidental y, parcialmente, en la representación iconográfica del instrumento de martirio. La terminología empleada por esta versión, que también mantiene Jerónimo, oscila entre uectis fullonis y fustis fullonis, e igualmente aclara que se trata del madero con el que los bataneros suelen exprimir o retorcer (exprimo o extorqueo) los paños. De modo que debemos considerar que ambos términos hacen alusión a una herramienta equivalente ${ }^{23}$.

El cambio más significativo corresponde a la designación de pertica fullonis, por primera vez documentada a finales del siglo VIII ${ }^{24}$. Desde luego, en las versiones latinas medievales de la Passio Iacobi no hay nada que señale un vínculo directo con el texto griego, pues pertica es kanón, kámax o kontós, con el sentido de palo alargado y vara de medir ${ }^{25}$. También se atestigua la variante vocálica partica, en autores como Thomas Ebendorfer (1388-1464) y que es re-

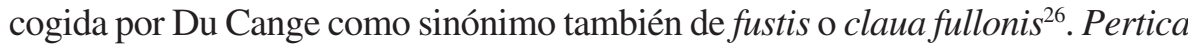
es el término más popular en la Edad Media, el que aparece en la descripción de Juan de Würzburg (ca. 1160-1170) ${ }^{27}$, peregrino que da cuenta de la inscripción en hexámetros leoninos que figuraba en la capilla del sepulcro del apóstol, una construcción mencionada por primera vez en el siglo IX y que fue convertida en memorial por los cruzados e identificada posteriormente con Qubbat as-Silsila ${ }^{28}$.

Menos relevante es, a juzgar por su uso, la denominación de baculus fullonis que se registra en el lenguaje poético de época carolingia, y cuya discusión queda fuera del marco de este estudio ${ }^{29}$.

23 Rufino, finales del siglo IV (E. Schwartz, T. Mommsen, Eusebius, pp. 166-167); Jerónimo, ca. 393 (De uiris Illustribus, 1, 611: véase: J.P. Migne, Ieronimus). En época tardoantigua, emplea el término de fustis Gregorio de Tours (B. Krusch, Gregorius, p. 53); en la segunda mitad del siglo IX, Heirico de Auxerre (R. Quadri, Heirici, p. 19) y en el siglo XII el peregrino Teodorico (R.B.C. Huygens, Peregrinationes, p. 16). Emplean el término de uectis: en el siglo VI, Gildas (T. Mommsen, Gildas, p. 67); en el siglo VIII, el Liber de ortu et obitu patriarcharum (J.P. Migne, Opera Theologica, p. 1290); en el siglo IX, el obispo Freculfo de Liseux (M.I. Allen, Frechulfus, pp. 450 y 474) y en el siglo XII, Pedro Abelardo (B. Boyer, R. MacKeon, Peter Abailard, p. 332). En las versiones anglosajonas de Cynewulf y Aefrico (siglo ¿VIII-IX?), el único término empleado es "steng" con el valor de bate o palo (J. E. Cross, Cynewulf's, p. 174).

${ }^{24}$ Siglo VIII: Rabano Mauro (J. McCulloh, Rabani, p. 41); siglos XII-XIII: crónica de Radulfo el negro de ca. 1140-1217 (R. Anstruther, Radulfi, p. 22), Pseudo-Agustín, ant. 1168 (A.B. Caillau, B. Saint-Yves, S. Aurelii, p. 197), el Liber Quare (G.P. Götz, Liber, p. 66), Legenda Aurea, ca. 1275 (T. Graesse, Iacobi a Voragine), crónica del dominico Martín de Opava (L. Weiland, Martini, p. 445); siglos XIV-XV: Crónica Erfordense (O. Holder-Egger, Chronica, p. 544).

${ }_{25}$ G. Goetz, Corpus, p. 79; H.G. Liddell, R. Scott, A Greek-English, p. 875.

${ }^{26}$ H. Zimmermann, Thomas, p. 114; M. du Cange, Glossarium, t. 6: s.v. partica, p. 185.

27 J.P. Migne, Joannes Wirzburgensis, col. 1063c.

${ }^{28}$ D. Pringle, The Churches, pp. 182-183; S. de Sandoli, Corpus Inscriptionum, pp. 116-117 (nº 153).

${ }^{29}$ Carmina Cenomanensia (E. Dümmler, Carmina, p. 627). 


\section{LÉXICO VERSUS IMAGEN: FACTORES PSICOLÓGICOS Y LÉXICOS DEL CAMBIO ICONOGRÁFICO}

Fustis se traduce como bastón o palo ${ }^{30}$, voces que aporta Isidoro, a las que añade su uso como arma con la que golpear (fustigo $)^{31}$. En cambio, uectis, aunque se emplee en la pasión de Santiago como sinónimo de fustis, tiene un matiz de palanca o barra; es la denominación que, por ejemplo, se emplea para el madero grueso y largo que mueve la prensa de viga, o para romper o demoler algo ${ }^{32}$. El icono del fustis o uectis fullonis se concreta en una porra nudosa. En las imágenes pre-tridentinas es una versión alargada de la claua, el clásico atributo de Hércules, o sea: una tosca maza con refuerzo de metal (de ahí su nombre) o sin él o de piedra ${ }^{33}$.

Pero ¿qué función podría cumplir esta tosca maza dentro de las labores del batán? Y lo que es más relevante, ¿son aptos los objetos plasmados en las distintas imágenes medievales de Santiago el Menor para haber cumplido esa función? En cualquier caso, nos enfrentamos a un problema de base insuperable ya que, al ser un instrumento de madera, no conservamos ninguno de época antigua o medieval, por lo que la fuente iconográfica y el testimonio escrito son los únicos documentos con los que podemos reconstruir su aspecto. Gracias a las fuentes documentales, sabemos que la única operación de la ars fullonia en la que se golpeaban los paños era el enfurtido que, hasta la segunda mitad del siglo $\mathrm{X}$, se realizó exclusivamente pisándolos con los pies (sub pedibus hominum) $)^{34}$. En época romana, el ruido de las fullonicae era proverbial $^{35}$, de modo que es incuestionable que los fullones se ayudaron con bates de madera, retorciendo el paño ${ }^{36}$, pero siempre con cuidado de no rasgarlo. A pesar de la introducción de la fuerza hidráulica -el golpeado mecánico se hacía con dos grandes mazos- el enfurtido se continuó practicando en el ámbito doméstico dentro de tinas ${ }^{37}$, como muestra una ilustración del ejemplar

\footnotetext{
30 A. Blánquez, Diccionario, p. 746; A. Blaise, Dictionnaire, p. 370; C.T. Lewis, A Latin, p. 798.

${ }^{31}$ Etymologiae, 5.27, 16; 20.13, 2 (véase: W.M. Lindsay, Isidori); A. Ernout, A. Meillet, Dictionnaire, p. 264.

32 A. Blánquez, Diccionario, p. 1805; A. Blaise, Dictionnaire, p. 839; C.T. Lewis, A Latin, p. 1961; Isidoro, Etymologiae, 5.27, 17 (véase: W.M. Lindsay, Isidori); A. Ernout, A. Meillet, Dictionnaire, p. 716.

33 Etymologiae, 18.7, 7 (véase: W. M. Lindsay, Isidori).

34 Se mantiene durante toda la Edad Media; por ejemplo, en Londres en 1295-1296 (P. Walton, Textiles, p. 330).

35 Plauto, Asinaria, 905 (véase: W.M. Lindsay, T. Macci Plauti).

${ }^{36}$ F.M. Feldhaus, Die Technik, p. 46.

${ }^{37}$ P. Iradiel, Evolución, p. 202 y nota 104.
} 
londinense del Splendor Solis (ca. 1582) ${ }^{38}$. Una simple ojeada a buena parte de las imágenes medievales del martirio de Santiago disuade inmediatamente de su posible empleo en un batán, so pena de rasgar las telas. Algunos de los más antiguos iconos lo que muestran es un bastón nudoso, apenas trabajado, totalmente inadecuado para golpear un tejido sin que las astillas de su corteza lo rasgaran, cosa totalmente prohibida por cualquier ordenanza. Este bastón nudoso aparece en el martyrologium de Ratisbona, ca. 1170 (fig. 1), en el que se sintetiza en una sola imagen la lapidación y el golpe con el madero ${ }^{39}$, o la miniatura del manuscrito de la Keble College Library de Oxford (siglo XIII) ${ }^{40}$.

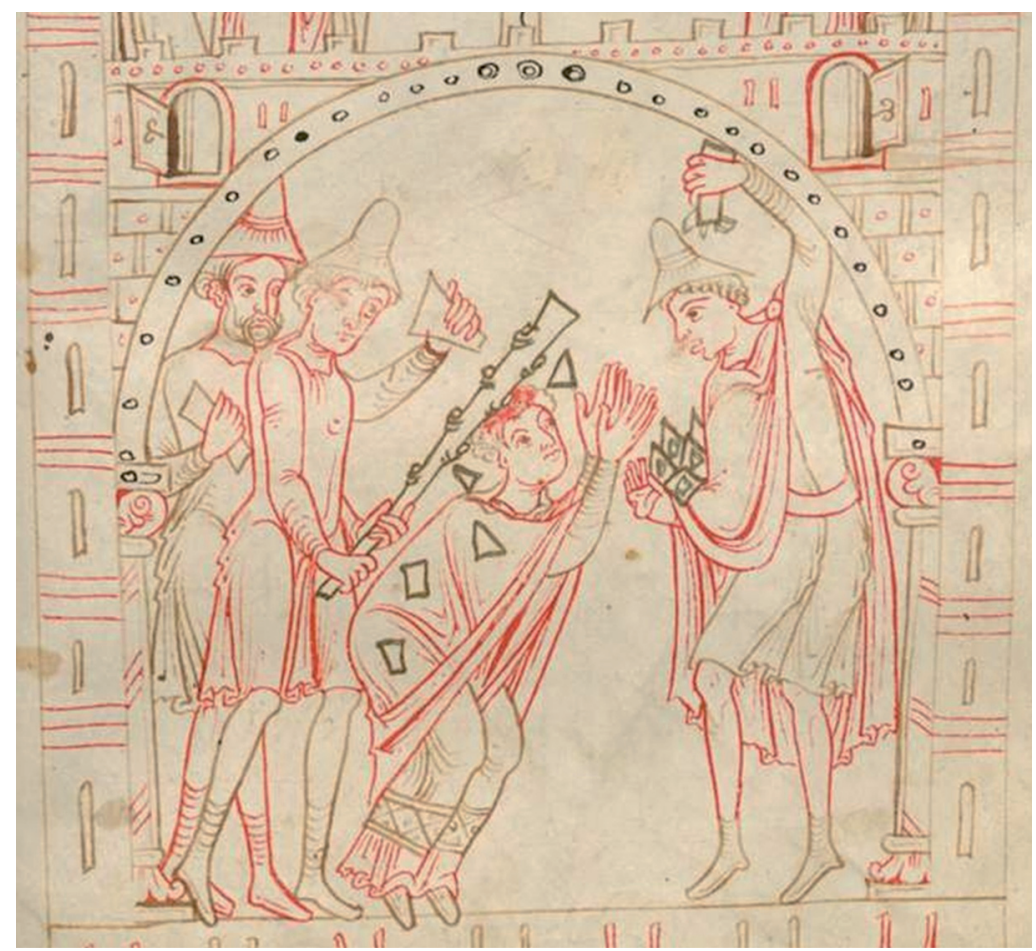

Fig. 1. La claua del martirio de Santiago el Menor. Martiriologio de Ratisbona o Vita et passio Apostolorum, item SS Christophori, Lucca, Marci, ca. 1170. Pergamino, 17,89x27,76 cm. Múnich, Bayerische Staatsbibliothek Munchen, BSB, Clm 13074, f. 82.

${ }^{38}$ British Library Ms. Harley 3469, f. 23r. Esta obra se puede consultar online: http://www. bl.uk/catalogues/illuminatedmanuscripts/searchMSNo.asp

${ }^{39}$ Bayerische Staatsbibliothek Munich BSB Clm 13074, f. 82.

${ }^{40}$ F. 73v (D.R. Cartlidge, J.K. Elliot, Art, fig. 6.19). 
En España, destaca una tabla de la catedral de Huesca (segunda mitad del siglo XIV) conservada en el Museo Nacional de Arte de Cataluña (fig. 2) ${ }^{41}$.

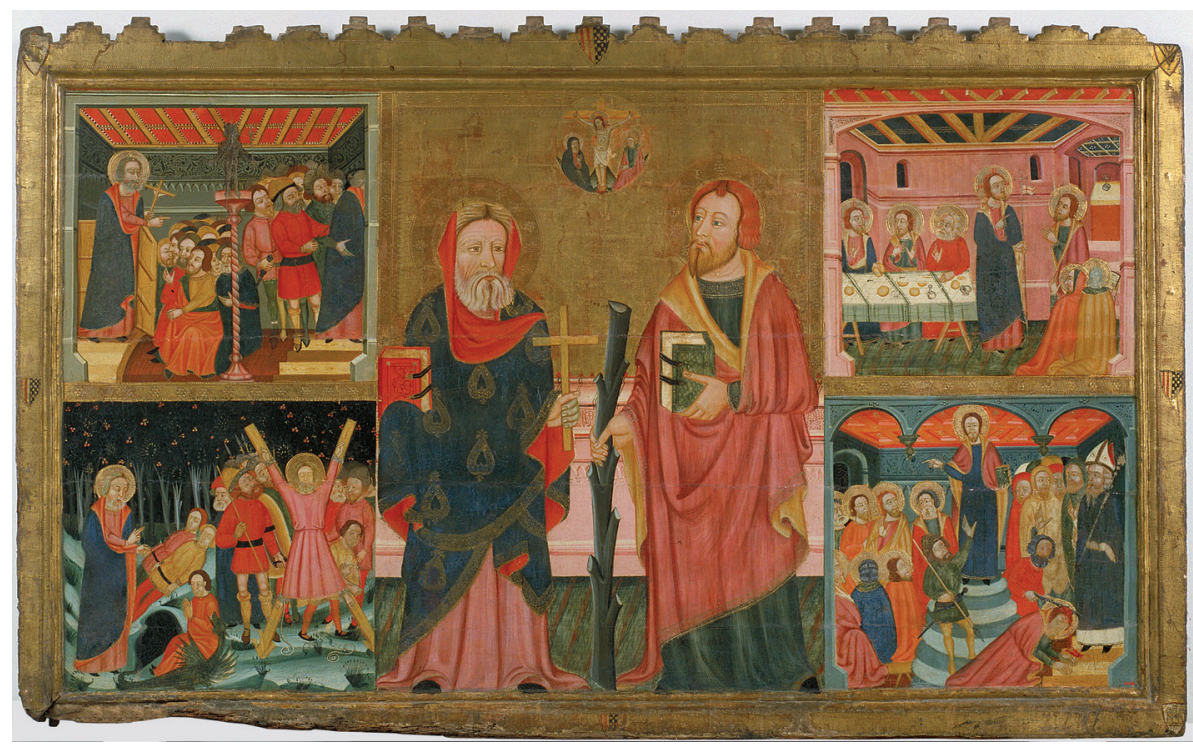

Fig. 2. Santiago el Menor con la claua. Retablo de San Felipe y Santiago el Menor, catedral de Huesca. Anónimo aragonés, segunda mitad del siglo XIV. Temple sobre tabla, 131,4x213 cm. Barcelona, Museu Nacional d'Art de Catalunya ${ }^{\circ}$ inv. 4526.

(C) MNAC 2009. Fotógrafos: Calveras/Mérida/Sagristà.

Otras imágenes del martirio son más escuetas y poco se puede deducir de ellas, como el bastón liso que empuña el batanero de la ilustración del pasionario de Stuttgart (ca. 1110-1120 $)^{42}$. Lo cierto es que, adecuado o no, este tipo de bate nudoso o porra será lo que quede establecido como atributo del santo tras la Contrarreforma ${ }^{43}$. Otra prueba de ello es que aparece habitualmente como arma de martirio de otros santos que tienen en común el apaleamiento como muerte, salvo que en el caso de Santiago la longitud del bate es

${ }^{41}$ MNAC no 4526 (Colección Plandiura); M.C. Lacarra, La influencia, p. 431 y fig. 2.

42 Württembergische Landesbibliothek Stuttgart Cod. Bibl. $2^{\circ}$ 57, f. 50v. Manuscrito inicialmente atribuido a Hirsau y después al scriptorium de Zwiefalten, ambos cerca del lago Constanza (A. Boeckler, Das Stuttgarter).

43 Francisco Pacheco indica que el atributo es una porra pues con un grueso tronco le esparcieron los sesos por tierra (F.J. Sánchez, Francisco Pacheco, pp. 321-322), una imagen perfectamente ilustrada por el óleo de 1639 de Pedro Orrente del Museo de Bellas Artes de Valencia ( $\mathrm{n}^{\circ}$ inv. 5/88), que no escatima en detalles como la claua en manos del verdugo o los sesos sobresaliendo del cráneo quebrado del apóstol, esparciéndose por el suelo. 
siempre notable, quizá por confluencia semántica de pertica. El aspecto psicológico del relato, la bestialidad de la ejecución, determina la representación del fustis o uectis fullonis como una maza sin desbastar.

En ocasiones, la fidelidad del instrumental del fullo es notable, ya que contamos con el elocuente testimonio de la representación en plena acción. Los mazos de enfurtir presentes en dos frescos italianos: en la iglesia de San Nicolà de Filettino en Frosinone, de la primera mitad del siglo XIII, y en la basílica de Santa Maria Assunta de Atri en Abruzzo, del siglo XIV (fig. 3a) ${ }^{44}$, son idénticos a los que muestra la escena de las lavanderas de lino del Splendor Solis (fig. 3b) ${ }^{45}$. En otros casos, la fragmentación del testimonio visual es de poca ayuda, como en el maltrecho fresco de la capilla Ovetario de la iglesia de los Eremitani de Padua, obra de Mantegna (1453-1457), donde el verdugo está a punto de ejecutar al apóstol con una maza de cabeza cilíndrica; mientras que otro personaje descansa, a la izquierda del santo, apoyado sobre una cerca de madera y sosteniendo, con su mano izquierda, una claua. Así figura en la reconstrucción de la pintura de mediados del siglo $\mathrm{XX}^{46}$, mientras que en un grabado de G. David de 1776, conservado en el Victoria and Albert Museum de Londres, el bate nudoso se convierte en una de las estacas que sostiene la cerca de madera ${ }^{47}$.

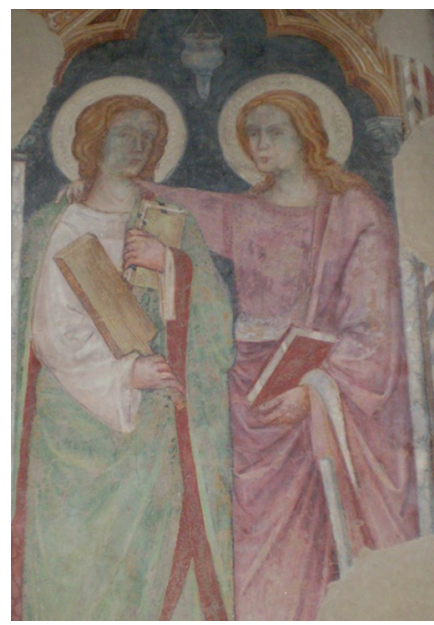

Fig. 3a. La maza de lavandero usada como emblema de Santiago el Menor, en un detalle del fresco de la basílica de Santa Maria Assunta de Atri en Abruzzo, siglo XIV.

${ }^{44}$ G. Kaftal, Iconography, cols. 576-577, nota 2 y fig. 914.

${ }^{45}$ British Library Ms. Harley 3469, f. 32v.

${ }^{46}$ E. Camesasca, Mantegna, pp. 4-5 y fig. 5-10.

47 Victoria and Albert Museum, DYCE $\mathrm{n}^{\circ}$ 1581. Información obtenida mediante la herramienta de búsqueda del propio museo: http://collections.vam.ac.uk/. 


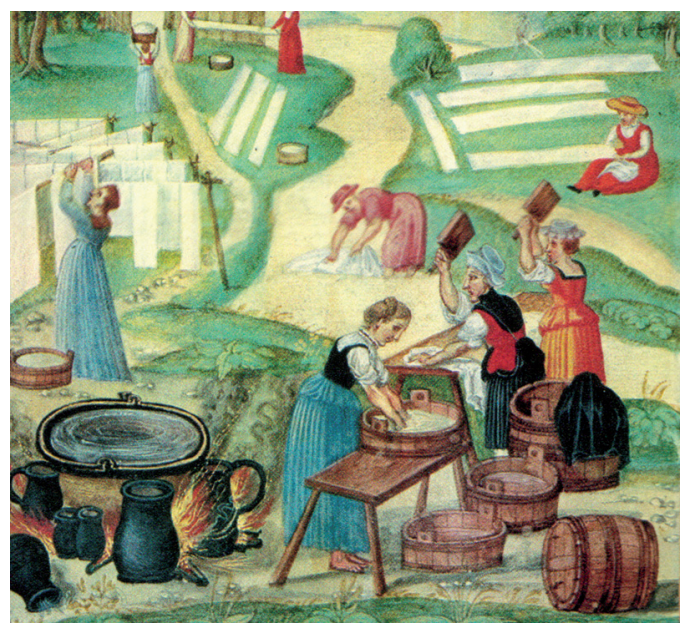

Fig. 3b. La maza de lavandero usada por las lavanderas en un detalle del f. $32 \mathrm{v}$ del Splendor Solis de Salomon Trismosin, datado en 1582.

Pergamino, 32x22 cm. Londres, British Library Ms. Harley 3469.

En el caso del término latino de pertica, no tenemos ni un solo ejemplo clásico asociado al campo semántico de la fullonica. Ya he señalado que el primer testimonio que conozco de su introducción en el relato de la pasión de Santiago data de finales del siglo VIII, aunque sólo se generaliza desde el siglo XII en adelante. En latín clásico, la voz pertica se limita a dos acepciones básicas: unidad de medida y palo para sostener vides ${ }^{48}$. Es probable que de este último significado pasara al de palo largo y estrecho del que cuelgan cosas, especialmente, paños. Fundamento esta hipótesis en que, dentro del léxico tardomedieval de la industria textil, aparece la voz "percha" y "perchar" con el significado de colgar los paños, ya abatanados, para sacarles el pelo con la carda: una de las últimas fases del trabajo. El instrumento constaría de una vara larga móvil, de sección circular, pulida y recta, que descansa sobre dos ganchos sujetos a la pared o al techo ${ }^{49}$. En latín clásico, sin embargo, no hay registro de la acepción de pertica como equivalente a la percha (de cardar) medieval, ni

48 P.G.W. Glare, Oxford Latin, p. 1350; P. Flury, M. Hillen, N. Holmes, Pertica, cols. 1784-1785. Isidoro únicamente registra la primera acepción (Etymologiae, 15.15.3; véase: W. M. Lindsay, Isidori), mientras que la segunda aparece en Catón (De Agricultura, 33.4; véase: Mazzarino, M. Porci Catonis). Descarto la posibilidad de que sea una referencia a la vara de medir, otro significado de pertica, pues ésta no es específica del gremio textil, sino que es una acepción del término compartida por otros muchos oficios.

49 D. Diderot, J. R. D’Alembert, Encyclopédie, s.v.: Draperie, t. 24, lám. VII, fig. 24. A. Uscatescu, En torno, p. 206. 
tampoco de su uso como palo horizontal para colgar telas. Sí, en cambio, tenemos un testimonio gráfico de un fresco pompeyano, en el que un palo largo y estrecho sostiene un paño sobre el que trabaja un fullo con la carda ${ }^{50}$. En español aparece documentado, desde el siglo XV, como percha de cardador o de pelaire u oficial de percha, denominaciones propias del oficio ${ }^{51}$. Huelga insistir en que la "percha" castellana derivaría de pertica, se piensa que a través del francés "perche" 52 -la etimología propuesta se concreta en una contracción de pertica $>$ *pert(i)ca > *pert'ca > *per'ca > perche-. En este caso, nos encontramos ante una transferencia semántica por extensión dentro del mismo léxico del oficio textil, pues se entiende que la pertica-percha era un instrumento específico que no se utilizaba primariamente para golpear los paños al lavarlos ${ }^{53}$, sino para colgarlos y cardarlos.

La imagen medieval más antigua de una pertica empleada como instrumento del suplicio de Santiago el Menor corresponde al mosaico de la basílica de San Marcos de Venecia (finales del siglo XII o inicios del XIII), ubicada en el muro de la nave sur de ese templo (fig. 4) ${ }^{54}$.

Se trata de un largo palo trabajado, totalmente liso y pulido. Pero no siempre el instrumento representado tiene esa forma $\mathrm{y}$, recurrentemente, se registran palos con el extremo ligeramente curvado ${ }^{55}$, como un bastón de hockey. Nuevamente, la falta de ejemplares conservados impide asegurar que los bates auténticos tuvieran dicha morfología, pues algunos son pulidos como el de la portada sur de la catedral de Chartres $^{56}$ o los representados en diversos manuscritos del siglo XIV ${ }^{57}$. Otros presentan corteza y nudos, como el de la 610).

${ }^{50}$ Pilar de la officina fullonica de L. Veranius Hypsaeus (V. Sampaolo, Fullonica, pp. 604-

${ }^{51}$ L. Nieto; M. Alvar, Nuevo tesoro, p. 7560. Covarrubias asocia este término con el cardado de las prendas de lana: "es una lata delgada y larga y limpia y lisa. Ésta sirve a los perailes que llaman oficiales de percha". En inglés medieval, éste es uno de los sentidos de "perch" (E. Crowfoot, F. Pritchard, K. Staniland, Textile, p. 18), pues también se emplea como sinónimo de bate o maza de batanero (J.A. Simpson; E. S. C. Weiner, The Oxford English, pp. 524525). En francés, en cambio, se registra a mediados del siglo XII como barra para colgar ropa (TLF, Trésor, vol. XIII, pp. 51-52).

52 Autoridades, Diccionario, p. 212; A. Branchet, E. Egger, Dictionnaire, p. 404; RAE, Diccionario, pp. 1571-1572.

53 La expresión que Walton recoge, "ad perticam", no tiene porqué referirse, como esta autora sugiere, al enfurtido sino, como aquí sostengo, al cardado (P. Walton, Textiles, pp. 330-332; notas 91 y 92).

${ }^{54}$ O. Demus, The Mosaic, pp. 79-80 y lám. 27.

${ }_{55}$ R.P. Bedford, Saint James, p. 12.

${ }^{56}$ E. Mâle, Notre-Dame, lám. 63.

57 Diversos manuscritos franceses de la Bibliothèque National de France: Bible historiale (primera mitad del siglo XIV), Ms. fr. 157, f. 253; Vies des Saints (primera mitad del siglo XIV), Ms. fr. 183. f. 121; Legenda Aurea (1480-1490), Ms. fr. 244, f. 141v. Todas se pueden visualizar a través de la Base de Datos "Mandragore": http://mandragore.bnf.fr/jsp/rechercheExperte.jsp 




Fig. 4. La pertica fullonis del martirio de Santiago el Menor.

Detalle del mosaico de la nave meridional de la basílica de San Marcos de Venecia (fin siglo XII e inicios del XIII).

tabla del pintor holandés Geertgen tot Sint Jans, datado en 1490, donde el pequeño Santiago, al lado de su madre, sostiene un tosco bate curvado por su extremo inferior (fig. 5) ${ }^{58}$.

Una de las imágenes más antiguas del martirio de Santiago forma parte del Menologio de Basilio II (siglo XI). El fullo, situado en la escalinata del ambón, golpea la cabeza del apóstol con un instrumento corto y delgado que no es ni una pertica, ni una claua; en la parte superior del objeto, se observa un engrosamiento y por eso los editores del manuscrito lo identifican con una korýne, una maza con esfera metálica en la punta y atribuyen la elección del ilustrador a una falta de espacio compositivo (fig. $6)^{59}$. Creo que esa supuesta escasez de espacio en el folio de pergamino no explica la aparición de este tipo de maza, un arma de ataque auténtica y no un útil de trabajo. Es el mismo tipo de arma con la que San Marcos es atacado en Alejandría, según figura en los mosaicos de la basílica de San

${ }^{58}$ Rijksmuseum n ${ }^{\circ}$ SK-A-500; L. Réau, Iconographie, p. 145.

${ }_{59}$ Biblioteca Vaticana, Il menologio, p. 35 y nota 3. 
Marcos de Venecia ${ }^{60}$. La aparición de bastones, ramas o maderos menos elaborados en otras imágenes de este menologio hacen aún más evidente esta identificación ${ }^{61}$. Las mazas de combate más antiguas tenían la cabeza de piedra, aunque posteriormente fueron de metal. Pese a existir testimonios arqueológicos anteriores, no será hasta el siglo XII cuando se extienda su uso en batalla con el objeto de quebrar las armaduras ${ }^{62}$. Posiblemente, sea una variante del arma que sostienen los soldados de la última escena del llamado "tapiz" de Bayeux (tercer cuarto del siglo XI), cuyos bordados de lana sobre lino relatan la conquista de Inglaterra por parte de los ejércitos de Guillermo de Normandía, en 1064-1066, concretamente esa última escena correspondería a la batalla de Hastings ${ }^{63}$.

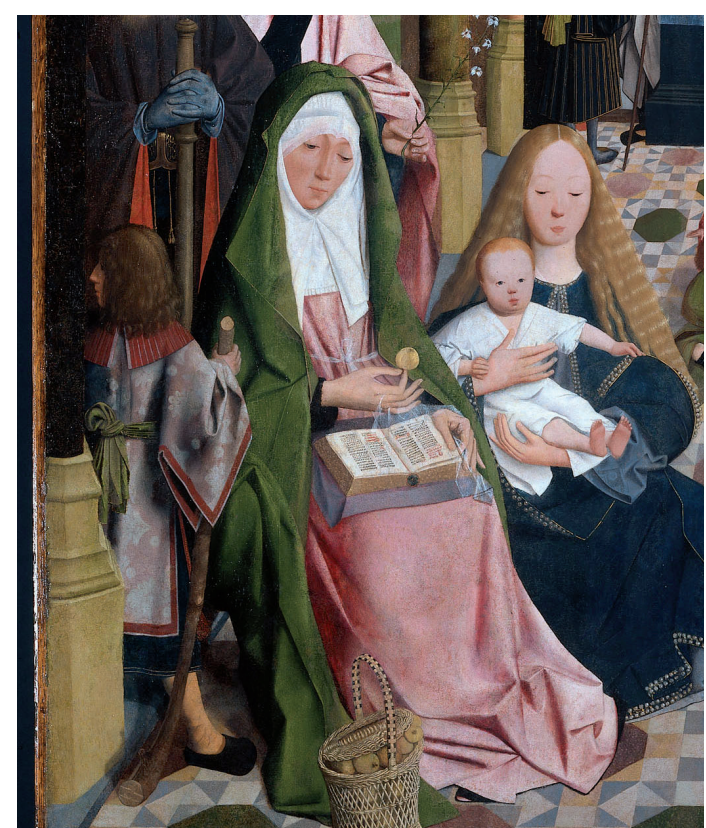

Fig. 5. El bastón curvado como emblema de Santiago el Menor niño. Detalle de la Santa Parentela de Geertgen tot Sint Jans, 1490. Oleo sobre tabla, 137x105 cm. Amsterdam, Rijksmuseum n ${ }^{\circ}$ SK-A-500.

${ }^{60}$ B. Bertoli, I mosaici, p. 26.

${ }^{61}$ San Eusebio diácono es golpeado con un palo (xýlon) o San Meorzio con un bastón nudoso (báklos ágrios) (Biblioteca Vaticana, Il menologio, pp. 25 y 85, respectivamente).

${ }^{62}$ K. DeVries, Medieval, pp. 25-26.

${ }^{63}$ W. Grape, The Bayeux, pp. 25 y 167. 


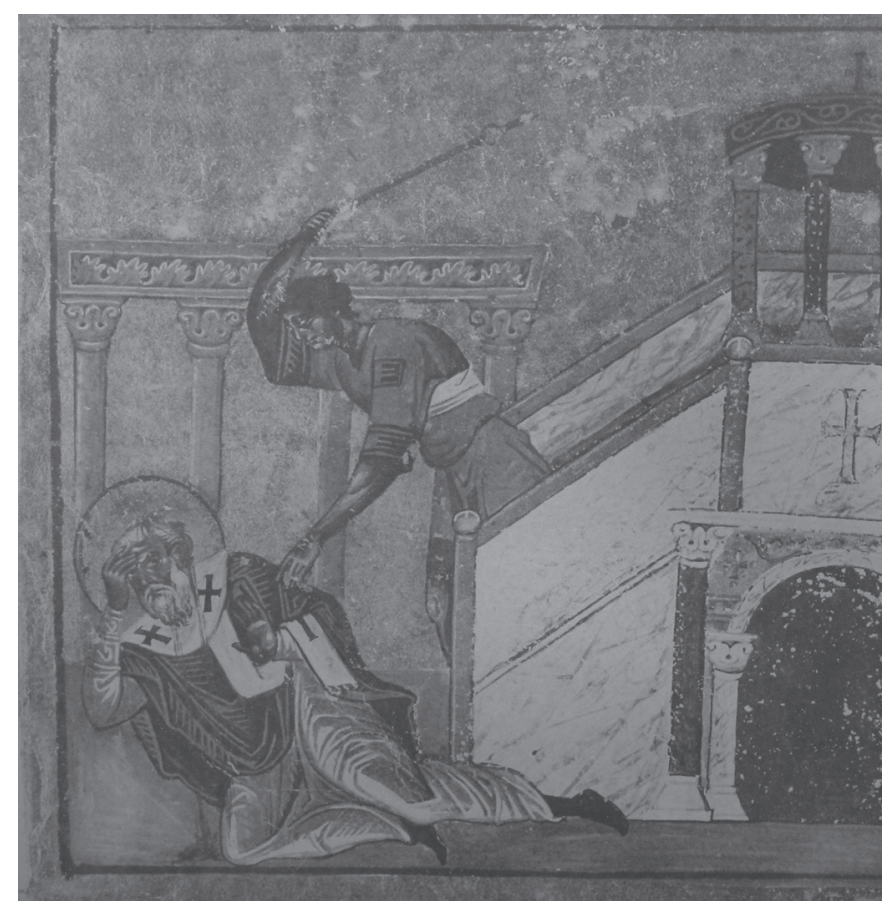

Fig. 6. Detalle del martirio de Santiago el Menor en el Menologio de Basilio II, ca. 976-1025. Pergamino, 24x16 cm. Ciudad del Vaticano, Biblioteca Vaticana Cod. Vat. Gr. 1613, f. 131v.

\section{UN CAMBIO INESPERADO: EL ARCVS CVTHONIS}

La mutación más radical se hace visible en un momento indeterminado de inicios del XV y corresponde a la introducción de un nuevo instrumento que ha sido objeto de controversia en la historia de la tecnología textil: el arco de lana o algodón. Su asociación con Santiago el Menor se deriva de la relación que, irónicamente, este santo mantuvo con el gremio textil medieval, pero nada tiene que ver con cuestiones léxicas o semánticas.

La región nuclear donde se detecta este cambio es la Suabia histórica de inicios del siglo XV, con una extensión entre el lago Constanza y el Tirol meridional ${ }^{64}$. El ejemplo más antiguo conocido corresponde a la portada oeste de la parroquia de Ulm, $c a$. 1417-1422 (fig. 7).

\footnotetext{
${ }^{64}$ H. Rizzoli, Der Fachbogen, pp. 52-60.
} 


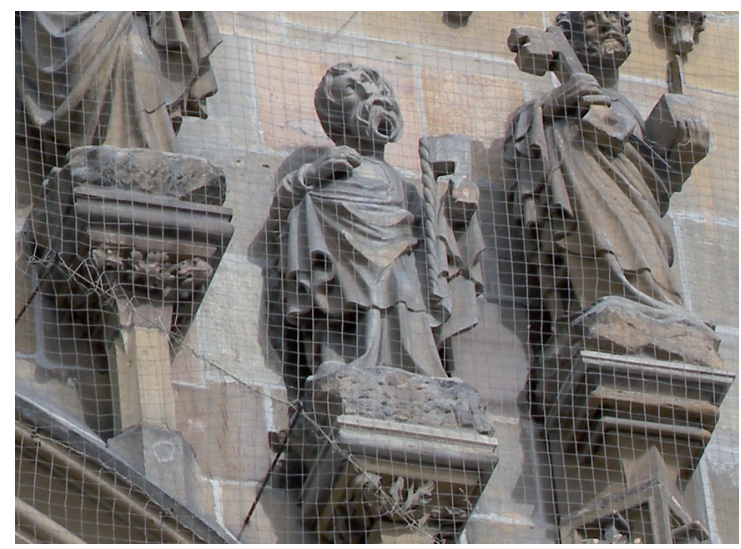

Fig. 7. Santiago el Menor con el arco. Escultura in situ de la fachada del pórtico occidental de la parroquia de Ulm, $c a$. 1417/1422 (fotografía de la autora).

Este dato obliga a revisar los ejemplos que Bedford aportó y que hacían suponer que esa innovación iconográfica se originara ya en la segunda mitad del siglo XIV, al considerar la aparición más antigua del arco asociado a Santiago el Menor la imagen del portal meridional de la catedral de Augsburgo (ca. 1368-1370) $)^{65}$. Esta afirmación se ha revelado errónea por el lógico desconocimiento que el autor inglés tenía de la restauración poco ortodoxa que se realizó en 1890 en esa catedral alemana y que supuso la introducción forzada del arco textil en una de las esculturas del lado oriental, la figura vecina al apóstol Andrés, tal y como muestra la fotografía publicada por Hartmann en 1910 (fig. 8a). En realidad, esa figura jamás debió sostener ningún objeto con su mano derecha, pues ésta presenta los dedos meñique y anular plegados sobre sí mismos hacia la palma de la mano y el resto extendidos en gesto de bendición desde lo alto (fig. 8b) ${ }^{66}$. Sin embargo, este arco espurio se mantuvo in situ hasta bien avanzado el siglo XX, cuando se retiró tras la nueva restauración de $1983^{67}$. La introducción del arco en la portada creo que se debe

\footnotetext{
${ }^{65}$ Aunque antiguamente la datación de la portada se situara $c a$. 1356, fecha en la que el coro aparece mencionado en las fuentes, la decoración de la misma no puede ser anterior a la constitución de los gremios de Augsburgo de 1368 ya que los escudos de éstos aparecen a los pies de los apóstoles, motivo por el que Chevalley propone una datación situada entre 1368-1370 (D.A. Chevalley, Der Dom, p. 141 y lám. 229 y 235).

${ }_{66}$ Actualmente, sólo quedan los hierros de los que arrancaban los dedos índice y mediano (observación personal).

67 R.P. Bedford, Saint James, p. 28; P. Hartmann, Die gotische, lám. 17; F. Klober, Baugeschichte, pp. 7-29 y fig. 140 y fig. 159. Lamentablemente, las litografías conservadas de 1853 no permiten observar el detalle de la figura a la que se le añadió el arco.
} 


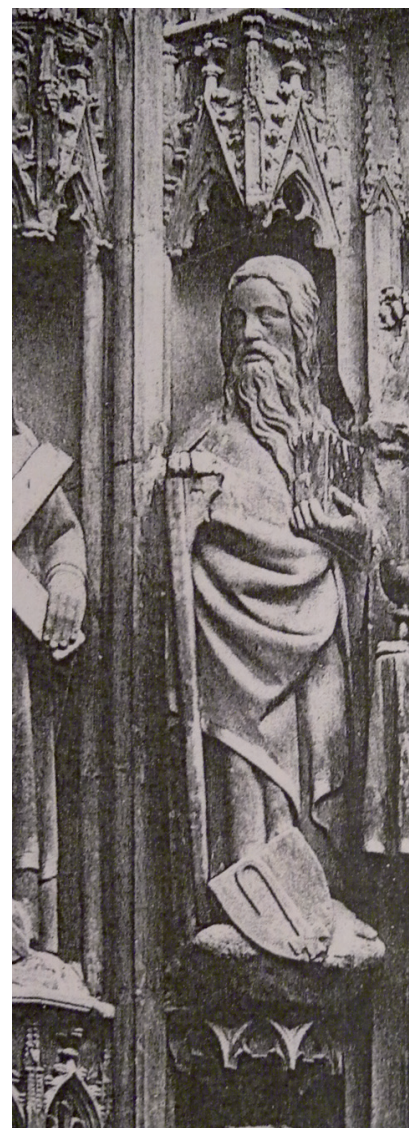

Fig. 8a. Escultura de apóstol erróneamente identificada con Santiago el Menor en la portada meridional de la catedral de Augsburgo, ca. 1368/1370.

Aspecto de la escultura con el arco, en una fotografía tomada a inicios del siglo XX.

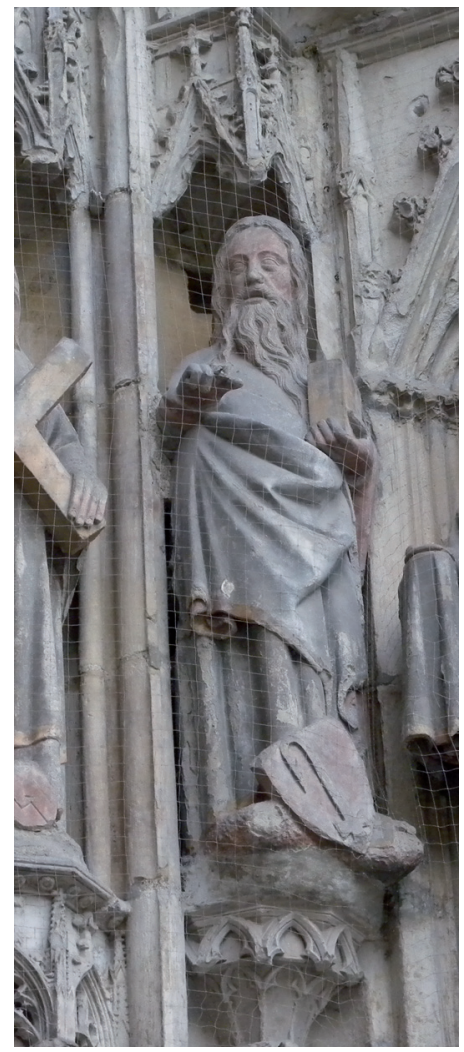

Fig. 8b. Escultura de apóstol erróneamente identificada con Santiago el Menor en la portada meridional de la catedral de Augsburgo, $c a$. 1368/1370. El estado actual tras la eliminación del arco espuriamente añadido (fotografía de la autora).

entender en su contexto histórico, como una de tantas otras manifestaciones del nacionalismo germano inmediatamente posterior a la unificación de su Imperio. En este mismo sentido, la cronología de finales del siglo XIV para los hallazgos más septentrionales a orillas del Báltico sostenida por Bedford también es matizable, con el problema añadido de que los frescos donde aparecía Santiago el Menor con el arco no sobrevivieron a los bombardeos del final de la Segunda Guerra Mundial (iglesias de Marienkirche de Wismar y de Rostock-Lichtenhagen). A juzgar por las fotografías y datos aportados por 
Schlie, a finales del siglo XIX, los frescos podrían asignarse sin problemas al siglo XV: en el primer caso, las pinturas son obviamente posteriores a 1388 $\mathrm{y}$ en el segundo, claramente se ejecutan desde la primera mitad del siglo XV (1419-1454, fecha de la finalización de la última bóveda de la iglesia) y no a finales del siglo XIV como señaló Bedford, que es cuando la iglesia comenzó a construirse ${ }^{68}$.

Hechas estas salvedades, el arco asociado a Santiago el Menor es una peculiaridad que se mantiene desde el siglo XV entre las principales figuras de la pintura alemana conocidas (Schongauer, Durero, Schaffner, Traut) o anónimas (Meister der Heiligen Sippe o del Oberaltaicher Schmerzensmann) ${ }^{69}$, todos ellos vinculados de una u otra forma a la Suabia histórica ${ }^{70}$. Salvo escasas excepciones, no parece que el cambio de atributo tenga mucho predicamento fuera de tierras germanas, aunque desde mediados del siglo XV se contabiliza un mayor número de representaciones del arco, sobre todo retablos y bronces, en regiones periféricas ${ }^{71}$. El cambio afecta a todas las representaciones del apóstol: martirio y atributo, incluso cuando éste es sostenido por Santiago niño en la iconografía de la Santa Parentela (fig. 9) ${ }^{72}$.

${ }^{68}$ F. Schlie, Die Kunst, vol. II, pp. 58-60 (fresco de la iglesia de Wismar en p. 60) y vol. III, pp. 703-705 (fresco de la iglesia de Rostock-Lichtenhagen en p. 703); G. Kiesow, Sankt Marien.

${ }^{69}$ R.P. Bedford, Saint James, pp. 27-28; D. Zinker, Masterpieces, pp. 130-133. R. Budde et al., Wallraf-Richartz, p. 35.

70 Salvo el Meister der Heiligen Sippe, considerado un artista anónimo que desarrolló su obra en Colonia, diseño de los vitrales de la catedral incluídos (The National Gallery, Late Gothic, pp. 62-64).

${ }^{71}$ Los ejemplos del vecino Tirol son algo más tardíos, datados entre 1469 y 1490: fresco de la iglesia de Santiago de Bolzano o el de San Martín de Kampill en esa misma provincia (con una datación estilística más controvertida que lo sitúa a inicios del siglo XV); así como la talla de Santiago el Menor del altar mayor de la iglesia de Santiago de Nösslach en Greis de Brenner (H. Rizzoli, Der Fachbogen, p. 52 y figs. 1, 3 y 8, respectivamente. En la obra de Rizzoli, hay una pequeña errata tipográfica, pues la fig. 2 corresponde a la 8 y viceversa). Como curiosidad destaca un esqueleto que representa una pobre alma sosteniendo un arco en el libro de horas de Georg Hölzl conservado en el monasterio tirolés de Neustift en Bressanona, de 1469 (H. Rizzoli, Der Fachbogen, fig. 4).

72 Representaciones de Santiago niño con el arco: joven Meister der Heiligen Sippe del Wallraf-Richartz Museum de Colonia, $c a .1500$ (WRM n ${ }^{\circ}$ 165), retablo de Wolf Traut del Bayerisches Nationalmuseum de Múnich (1514), tabla del Meister des Oberaltaicher Schmerzenmannes de la Staatsgalerie de Stuttgart (1518), no inv. 1174 (L. Réau, Iconographie, p. 144; R. Budde et al., Wallraf-Richartz, p. 35; E. Rettich, Meister, pp. 240-241). 


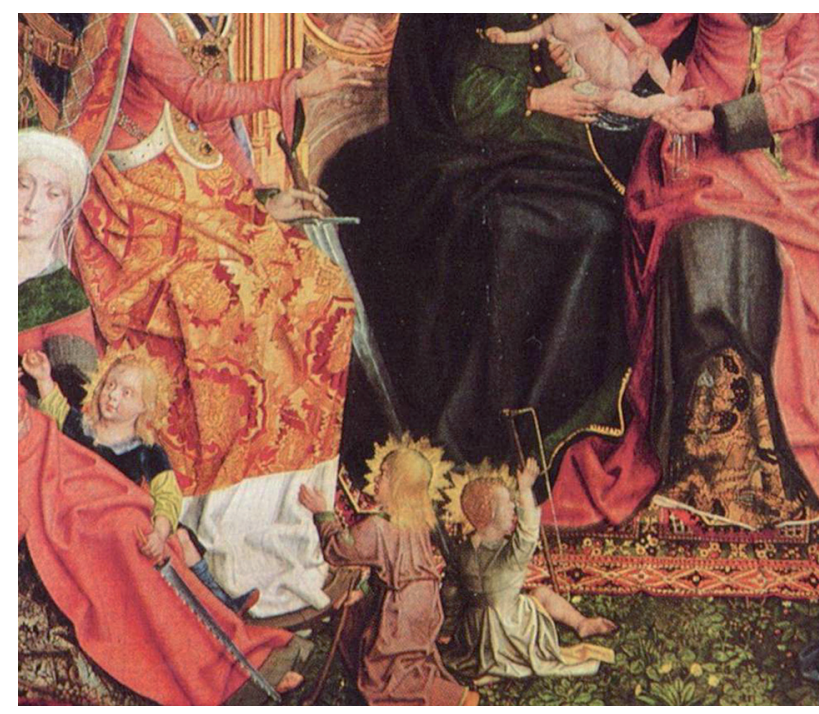

Fig. 9. Santiago el Menor niño con el arco. Detalle de La Santa Parentela del joven Meister der Heiligen Sippe, $c a$. 1500. Técnica mixta y óleo sobre tabla, 141x186 cm. Colonia, Wallraf-Richartz Museum WRM no 165.

La peculiaridad del arco textil, junto a la incomprensión de su funcionamiento, ha provocado numerosos equívocos a la hora de su interpretación; a veces, se ha identificado con una bandera, un hacha e incluso con el arco de un violín. Se trata de un gran arco triangular de madera y cuerda de tripas que debía medir entre 1,55-1,83 $\mathrm{m}^{73}$; debido a su envergadura y para ayudar al operario a mantener el arco paralelo a la mesa de trabajo, éste quedaba suspendido de una cuerda anclada al techo o a una vara larga amarrada a la cintura del trabajador, con el objetivo de desplazar el arco fácilmente sobre la masa de fibra, como se observa en alguna ilustración del trabajo en Venecia o China, respectivamente (fig. 10) ${ }^{74}$. El arquero hacía vibrar la cuerda del arco golpeándola con un pequeño martillo. Mediante las

73 Las medidas corresponden a los arcos mencionados en las ordenanzas de Barcelona, Verona o Venecia (D. Cardon, La draperie, p. 162; M.F. Mazzaoui, The Italian, nota 8 y p. 194; nota 9 y p. 194). Los arcos asiáticos son mayores (más de $2 \mathrm{~m}$.) y se manejaban de forma ligeramente diferente (I. Turnau, Hand-Felting, p. 92)

${ }^{74}$ El más famoso es, sin duda, el emblema de los bombaseri de Venecia, pintado en 1517, restaurado en 1669, y conservado en el Museo Correr (D. Cardon, La draperie, fig. 74). Cardon observa que Fagniez indica que existe una ilustración china del siglo X. No he logrado encontrar dicha referencia en la obra de Fagniez. Quizá esta afirmación se deba a un error tipográfico de la, por otro lado, magnífica obra de Cardon (D. Cardon, La draperie, nota 77; G. Fagniez, Études, p. 219, notas 5 y 6). En cualquier caso, las ilustraciones chinas que conozco son los 
vibraciones, las fibras se separaban y el resultado era una masa homogénea y esponjosa de lana o algodón lista para hilar ${ }^{75}$. Su empleo se ha mantenido hasta el siglo XIX en distintos puntos del mundo donde la manufactura tradicional ha sido más reticente a la industrialización ${ }^{76}$. En este sentido, resulta curioso el testimonio del comerciante lionés Flachat, de mediados del siglo XVIII, quien establece una geografía sobre el uso particular del arco en Europa y, sorprendentemente, constata: L'Europe carde, le Levant et l'Asie arçonnent ${ }^{77}$. Entrado el siglo XX, Peter-Müller señala su utilización residual en el sureste de Europa y Mediterráneo oriental, pero también en el norte de Europa y en Indonesia ${ }^{78}$.

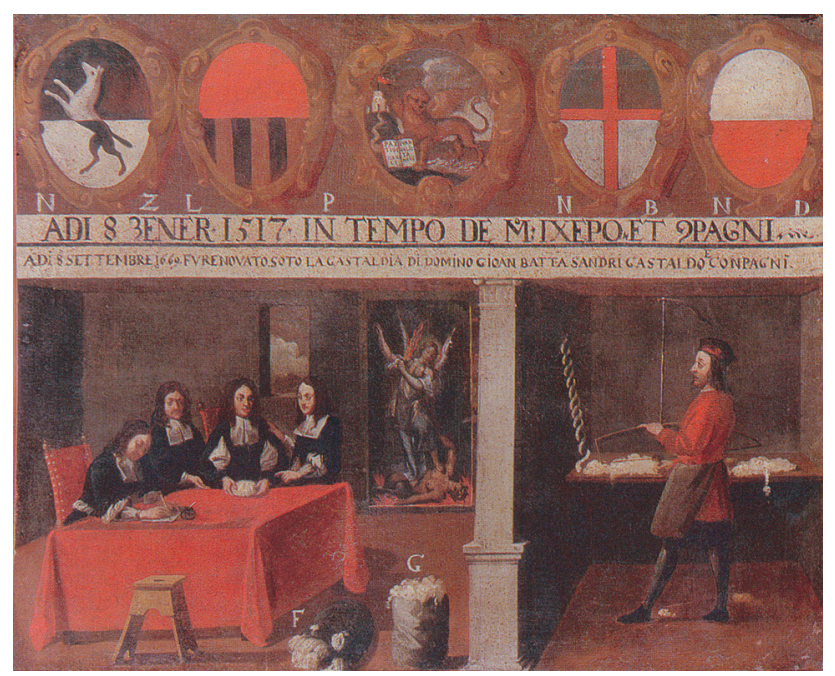

Fig. 10. Batidor de algodón en el emblema de los bombaseri de Venecia, 1669.

Óleo sobre lienzo, 68x82,9 cm. Venecia, Museo Correr n ${ }^{\circ}$ inv. Cl. I. 2124.

Así pues, la función básica del arco es la de limpiar y preparar la fibra para su hilado, en muchos casos es independiente del peinado o cardado. Pero este cometido lo cumple perfectamente el vareado, batido

grabados del maestro cantonés, Pu Qua de 1799 reproducidos en el libro de Feldhaus (operario chino batiendo el algodón con el arco, 1801: véase: F.M. Feldhaus, Die Technik, fig. 49).

75 J.B. Breton, China, pp.115-117; D. Diderot, J.R. D’Alembert, Encyclopédie, vol. 1, p. 621; F.M. Feldhaus, Die Technik, p. 46

${ }^{76}$ G. De Poerck, La draperie, p. 53, nota 1.

77 J.C. Flachat, Observations, apud; L. Hilaire-Pérez, Cultures, p. 102.

${ }^{78}$ I. Peter-Müller, Sankt Jakob, p. 10 y lám. 10, 21; I. Turnau, Hand-Felting, p. 92. 
o baqueteado ${ }^{79}$ : con dos varas flexibles se golpea la fibra, sobre una estera o sobre una parrilla hecha con listones de madera, una acción documentada textualmente en el siglo XIII, y que continuó en uso, especialmente para esponjar la lana de los colchones, hasta bien entrado el siglo $\mathrm{XX}^{80}$. Los estudios especializados concluyen que la principal función del arco es mezclar de forma homogénea las fibras, y que éste es más efectivo que el vareado e imprescindible para las fibras de pelo corto ${ }^{81}$. Por tanto, el arco es indispensable para tratar el algodón, aunque también se usó para diversas lanas de pelo corto y la fabricación de fieltro pues ayudaba a mezclar distintos tipos de pelos de forma precisa y homogénea, tanto que en ocasiones se llegó a vetar su uso para evitar mezclas prohibidas ${ }^{82}$. Por ello, no es extraño que las voces arconnarius y arconnare se documenten, desde el siglo XIII, en relación con la preparación de la lana ${ }^{83}$.

Desde el punto de vista iconográfico, sería de gran interés poder trazar una geografía medieval del uso del arco. No obstante, existe un problema insalvable y es que en el lenguaje medieval del oficio, según se desprende de los documentos generados por las corporaciones urbanas de distintas ciudades, no se suele diferenciar entre el bateriaus, batador o batedor y el arconnarius, de modo que es imposible excluir que sean referencias al batido con varas o con arco (battitor ad arcum) ${ }^{84}$. Si el uso del arco está extendido a toda Europa medieval, ¿por qué sólo es adoptado por artistas alemanes? No creo que sea el producto del azar o un capricho regional, sobre todo por la carga simbólica que adquirirá posteriormente este instrumento en los emblemas centroeuropeos de las corporaciones textiles en los siglos XVI-XVIII.

El vínculo de la manufactura del fieltro y el arco con el emblema particular de Santiago el Menor en las artes visuales alemanas fomentó la teoría de que ese icono se habría desarrollado localmente, porque, a diferencia del Mediterráneo, la

79 En general, sobre la descripción del proceso de tratamiento del algodón: R. Córdoba, La industria, pp. 94-95; C. Carrère, Barcelone, pp. 374-377.

${ }^{80}$ La imagen más extendida es la de la Encyclopédie, pero existen otras obras del siglo XIX, de Egipto a Suecia, de China a Praga (D. Diderot, J.R. D'Alembert, Encyclopédie, vol. I, fig. 3; I. Turnau, Hand-Felting, fig. 19-20).

${ }^{81}$ G. De Poerck, La draperie, p. 52. Se emplea también para el pelo de cabra (E. Crowfoot, F. Pritchard, K. Staniland, Textile, p. 17).

${ }_{82}$ M.F. Mazzaoui, The Italian, p. 9; G. De Poerck, La draperie, p. 53 y nota 3; I. Turnau, Hand-Felting, p. 26. El arco permitía hacer mezclas de fibras prohibidas que podían quedar mal tras el enfurtido o la tinción, pero también otros tipos de lana requerían obligatoriamente de su uso (D. Cardon, La draperie, p. 164). Por lo general, se prohibía la mezcla de lana con pelos de otros animales (ganado y porcino), (E. Crowfoot, F. Pritchard, K. Staniland, Textile, p. 18).

${ }_{83}$ M. du Cange, Glossarium, p. 372.

${ }^{84}$ D. Cardon, La draperie, p. 156; J.H. Munro, Textiles, p. 478; G. De Poerck, La draperie, p. 53 y nota 3 . 
romanización no habría alterado la tecnología germana desde época protohistórica (el fieltro se considera uno de los más antiguos materiales textiles, un estadio intermedio entre la piel y la invención del hilado) ${ }^{85}$. Esta hipótesis se basaba, por un lado, en la creencia de que los útiles del trabajo textil artesano son tremendamente inmovilistas, y por otro, en una vinculación etimológica del alemán felte y el latín medieval feltrum o filtrum (forma neolatina documentada en 918) ${ }^{86}$, puesto que en latín clásico fieltro es pileus o pileum. En la historia de la tecnología, se suele vincular la introducción de una innovación técnica con su correspondiente léxico, de modo que la expansión del vocablo feltrum, en vez de pileus, apoyaría la idea de que las naciones románicas habrían tomado la nueva denominación junto con el fieltro de los pueblos eslavos y esteparios por mediación de los germanos ${ }^{87}$, pese a que los hallazgos occidentales de piezas de fieltro eran más antiguos que los orientales $^{88}$. La teoría del arco prehistórico ganaba adeptos. El problema consistía en que los romanos contaban con talleres para la fabricación de fieltro (officinae coactiliariae), como el de Verecundus en Pompeya, y entre las imágenes detalladas de toda la industria textil romana no aparecía el arcado, únicamente se mostraba el peinado o cardado de las fibras ${ }^{89}$. Pero como la ausencia de pruebas no es prueba de ausencia, algunos autores como Moeller daban por sentado el uso del arco en la Prehistoria y asumían, pese al vacío existente hasta el siglo XV (aparición del arco asociado a Santiago el Menor), que su uso no debió haber caído en el olvido ${ }^{90}$. El rastreo de las técnicas del fieltro en Asia tampoco aclara la cuestión ${ }^{91}$, pues ese material se introdujo en China por contacto con las tribus nómadas (dinastía Zhou, siglos IV-III a.C.), mientras que los datos conservados sobre el uso del arco correspondían al siglo XVIII comprobándose que, a diferencia del Tíbet, Mongolia o las tribus turcas del Asia central que varean las fibras, los chinos empleaban el arco.

${ }^{85}$ R.J. Forbes, Studies, pp. 11 y 21 , nota 172 a y fig. 1.

${ }^{86}$ M. du Cange, Glossarium, pp. 428-429.

87 B. Laufer, The Early, p. 17; I. Turnau, Hand-Felting, p. 7.

${ }^{88}$ Von Stokar contaba con los hallazgos prehistóricos de Hessens y Behöring (1400-1200 a.C.), perdidos durante la Segunda Guerra Mundial, que eran más antiguos que las piezas de fieltro de los kurgans de la región siberiana de Altai, como en Pazyruk (siglos VII-II a.C.) (W. von Stokar, Spinnen, fig. 1; R.J. Forbes, Studies, p. 91; I. Turnau, Hand-Felting, pp. 7-9). Wild recoge ejemplos de fieltro más modernos, en Aardenburg (Holanda) y Vindonisa (Suiza) (J.P. Wild, Textile, pp. 60, 103 y 220-221).

89 V. Sampaolo, Officina, p. 774; fig. 2-6. Según Forbes, en Roma la lana se vareaba (R.J. Forbes, Studies, p. 21).

${ }_{90}$ W.O. Moeller, The Wool, pp. 15-16; contra: M. Hoffmann, The Warp-Weighted, p. 259. Mientras que Turnau asume que la invención del fieltro se dio de manera independiente en Europa y en Asia (I. Turnau, Hand-Felting, p. 89).

91 Feldhaus lo consideraba un invento chino, pero no podía explicar cómo habría llegado a convertirse en el emblema de Santiago el Menor (F.M. Feldhaus, Die Technik, p. 46). Entre los mongoles, el fieltro se golpeaba, humedecía y enrollaba, pero no se menciona el arcado (T.T. Allsen, Commodity, pp. 50-51). 
Sin embargo, Laufer consideraba que la aplicación del arco al fieltro procedería de la manufactura del algodón y no viceversa ${ }^{92}$.

La teoría que vincula la introducción del arco a la explotación del algodón es la que actualmente tiene más partidarios entre los especialistas en historia de los tejidos. Aunque el algodón ya se cultivaba en las regiones orientales del Imperio romano, su máxima expansión corresponde a época medieval (siglos IX-XII), coincidiendo con un óptimo climático ${ }^{93}$. En China, es una fibra importada que se expande con la dinastía Tang (618-907), pero su lenta difusión se explica por el inadecuado instrumental local, idóneo para fibras más largas (cáñamo y seda) ${ }^{94}$. Los datos de India tampoco son determinantes, pues vuelven a remitirnos a época colonial ${ }^{95}$, aunque ésta junto a Indonesia serían las dos candidatas a ser la cuna del invento ${ }^{96}$.

Algunos investigadores especialistas en el tema creen que la introducción del arco en la industria europea pudo haber venido acompañado de otras innovaciones técnicas registradas entre los siglos XI-XII. El arco de batir y la carda de púas metálicas fueron adaptaciones a la industria lanera de técnicas usadas en el mundo islámico para el algodón ${ }^{97}$, posiblemente a través de los centros de fabricación de fustán, concretamente, de las factorías tiraz palermitanas, que son retomadas por los normandos en el siglo $\mathrm{XI}^{98}$. A inicios del siglo XII, el arco se empleaba habitualmente en las industrias algodoneras de la Sicilia normanda, Apulia y seguramente en al-Andalus ${ }^{99}$. En opinión de

92 B. Laufer, The Early, pp. 7, 13 y 16.

${ }_{93}$ M.F. Mazzaoui, The Italian, pp. 15 y 20.

${ }_{94}$ M. Cartier, À propos, pp. 423-424.

${ }^{95}$ H.T. Harris, Monograph, pp. 25-26.

${ }^{96}$ En una reciente publicación sobre terminología textil del Cercano Oriente del III al I milenio a.C. es indicativa la ausencia del término "arco". Igualmente, se subrayan las dificultades de traducción de ciertos términos acadios relacionados con la acción de cardar o peinar las fibras, que se relaciona con la raíz "golpear, batir"; así como las diferentes bases que relacionan el término algodón con el lino, pelo de cabra o lana (A. Wisti Lassen, Tools, p. 275).

97 D. Cardon, La draperie, p. 163; M.F. Mazzaoui, The Italian, p. 76; J.L. Roch, Innovations, p. 47 y nota 6.

${ }^{98}$ M.F. Mazzaoui, The Italian, p. 26 y nota 77 en p. 174; J.H. Munro, Wool, p. 24; J.L. Roch, Innovations, p. 47.

${ }_{99}$ D. Cardon, La draperie, p. 162; M.F. Mazzaoui, The Italian, pp. 26 y 76, nota 4 y p. 187. Obviamente, la noticia sobre el uso del arco se limita a la mención del arco en los documentos de las corporaciones textiles. La más antigua data de 1110 y corresponde al cartulario de Conversano, en Apulia (M.F. Mazzaoui, The Italian, nota 6 y p. 193). Su uso queda asegurado por la aparición de operarios que manejaban el arco en distintas ordenanzas o estatutos de las principales ciudades laneras de Europa occidental: Toulouse (1227), Saint-Omer (1282-1284), Brujas (1284), Arras (1292), Siena (1298), París (fin siglo XIII), Valenciennes (post. 1302), Puigcerdá, Morella (Valencia), Vallibona y Mallorca (1315-1319), Malines (1331), Audenarde (1338), Narbona (1346), Aire-sur-le-Lys (1358-1359), Douai (1390), Barcelona (1447) y Cuenca (1458), (D. Cardon, La draperie, pp. 156-157 y 162, nota 82; G. Fagniez, Études, p. 219 y 
Cardon, reputada especialista en el tema, la adaptación del arcado para las lanas cortas en el noroeste de Europa se interpreta como un testimonio de la importación de la herramienta a esas regiones ${ }^{100}$. Pero lo que resulta más significativo para el presente estudio iconográfico es que, en las primeras regiones occidentales receptoras del arco del algodón, esto es Italia y España, el invento no tuvo ninguna repercusión en la imaginería del apóstol.

En cuanto a la explicación de este trascendente cambio iconográfico hay que señalar una circunstancia que va a condicionar muchas de las interpretaciones ofrecidas hasta la fecha. La incorporación de ilustraciones del funcionamiento del arco en la Encyclopédie des sciences ha determinado la relevancia de la hipótesis que vinculaba ese instrumento al poder del gremio de sombrereros centroeuropeo ${ }^{101}$, que decidió destacarse renunciando a la pertica $\mathrm{o}$ a la claua tradicional y sustituyéndola por el arco (Wollbogen o Fachbogen) ${ }^{102}$ como atributo de Santiago el Menor y su martirio ${ }^{103}$. Para Bedford, el cambio de emblema sería producto de una estrecha conexión entre las corporaciones del textil y los sombrereros, y la ausencia del cambio iconográfico en el Mediterráneo se explicaría por una diferencia de mentalidades nacionales, una contraposición del espíritu realista germano frente al idealismo meridional ${ }^{104}$. Por su parte, Cahier simplificaba aún más el asunto y consideraba que era una simple adaptación iconográfica a un instrumental de trabajo diferente, que ese autor atribuía a artistas flamencos y holandeses $(\text { sic })^{105}$. Pero la realidad es que no es precisamente en esas zonas geográficas donde se inicia el cambio, sino en las ciudades alemanas, y tampoco parece que sea un emblema privativo de los sombrereros pues es utilizado con el mismo derecho por sastres, tejedores de lana, pañeros, batidores, etc. (fig. 11) ${ }^{106}$, con ejemplos registrados desde el siglo XV en adelante. A lo que hay que añadir que los emblemas de sombrere-

nota 6; P. Iradiel, Evolución, p. 258; M.F. Mazzaoui, The Italian, p. 194, notas 7 y 9; G. De Poerck, La draperie, pp. 10 y 52).

${ }^{100}$ D. Cardon, La draperie, p. 163.

${ }_{101}$ D. Diderot, J.R. D’Alembert, Encyclopédie, vol. 1, p. 620. Tanto en la voz "arçon” como en la entrada "chapelier".

102 El vocablo Wollbogen se vincula siempre a la figura de Santiago el Menor, pero no se registra antes del siglo XVI (véase: J. Grimm, W. Grimm, Deutsches, vol. XIV-2, col. 1317).

${ }^{103}$ I. Peter-Müller, Sankt Jakob, p. 9; L. Réau, Iconographie, p. 703. No hay datos concluyentes, pero se piensa que los sombreros en la Edad Media estaban hechos mayoritariamente de fieltro (E. Crowfoot, F. Pritchard, K. Staniland, Textile, p. 76).

104 R.P. Bedford, Saint James, pp. 21-26.

105 C. Cahier, Caracteristiques, pp. 548 y 650 y nota 2.

106 Los sastres sajones de Magdeburg o Gardelegen (siglo XVII), pañeros de Friedeberg o Berlín (1442), sombrereros de Cracovia en Polonia (1505 y 1664), sellos de batidores de Brujas (1356 y 1407), insignia de los sombrereros en loza fabricada en Gmunden, Austria (A. Grenser, Zunft-Wappen, pp. 47 y 102-104, lám. 11 y lám. 25-16; I. Turnau, Hand-Felting, p. 91; R.P. Bedford, Saint James, fig. 20). En el museo de Ulm se exhibe una sala dedicada a las 
ros también pueden mostrar otros signos -los emblemas de Saint-Lo y Metz, por ejemplo, corresponden a sombreros de ala ancha ${ }^{107}$.

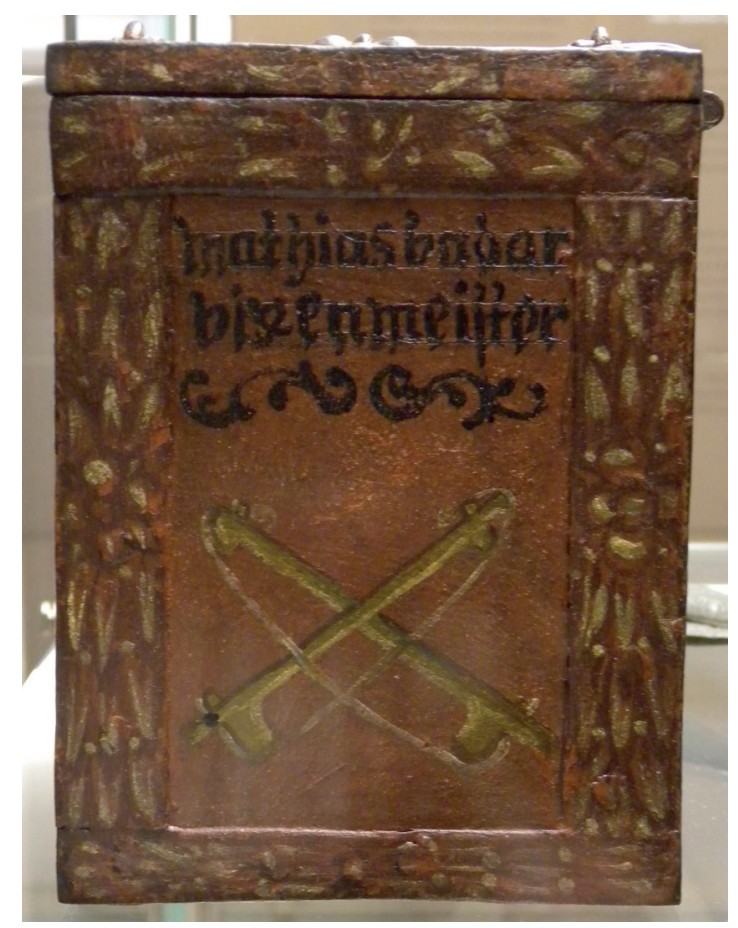

Fig. 11. Caja de madera de Mathias Bodar, maestro del gremio de tejedores de paños de lana bastos de Ulm de 1600, repintado en 1741. Técnica mixta sobre madera. Ulm, Ulmer Museum $n^{\circ}$ inv. 5216.

Ya he señalado que los datos cronológicos y la ubicuidad de la nueva iconografía de Santiago el Menor y el arco abogan por un origen en las regiones meridionales de Alemania. Hay que subrayar dos datos de interés. En primer lugar, en la segunda mitad del siglo XIV, en la Suabia histórica se concentraba buena parte de la creciente industria algodonera alemana (Ulm, Augsburgo, Núremberg). En ese momento histórico, se observa un movimiento continuo de artesanos especializados entre uno y otro lado de los Alpes: se tiene noticia de fustagnari alemanes en Venecia (Fondaco dei Tedeschi, siglo

corporaciones de los siglos XVI-XVIII en las que buena parte de los objetos corresponden a los gremios textiles (M. Ribbert, Die Kunstsammlung, pp. 47-51).

${ }^{107}$ L. Sánchez, Oficios. 
$\mathrm{XV}$ ) y viceversa ${ }^{108}$. No es ni por asomo casual que el declive de la industria algodonera italiana coincidiera en el siglo XIV con el despunte de la manufactura alemana ${ }^{109}$. En segundo lugar, el cambio tecnológico que habría conllevado la introducción del algodón procedente del sur de Europa, obviamente, habría antecedido a la representación iconográfica ${ }^{110}$. El arco de algodón habría sido rápidamente asimilado para el batido de las fibras de lana, pues las noticias conservadas de inicios del siglo XV apuntan a que en Suabia el arco se empleaba tanto para la lana como para el algodón. Patterson ofrece un dato sorprendente: en 1409, los trabajadores del gremio de lana de Constanza se quejaron de que el arco que, según ellos, debía estar reservado a la lana, estaba siendo usado para el algodón; una protesta que no debió prosperar pues los magistrados de la ciudad toleraron esa "nueva" aplicación. En las ordenanzas de 1403 de Ulm también se alude a disputas entre los tejedores a causa del monopolio del tejido del fustán ${ }^{111}$.

Creo que la coincidencia temporal de estos hechos nos permitiría considerar la innovación iconográfica que supone el cambio de la pertica fullonis por el arco de batir fibras textiles como atributo de Santiago el Menor una suerte de símbolo de una lucha de intereses económicos. El contexto de la contienda se enmarcaría en los enfrentamientos del monopolio secular de la lana, los poderosos Wollherren, que detentó la exclusividad de la importación del algodón italiano, frente a los pequeños comerciantes independientes que iniciaron la manufactura local del fustán (Bachent). Algunas de las manifestaciones de esas tensiones socio-económicas se concretarían en las reclamaciones sobre el derecho al uso de un determinado instrumento de trabajo, en este caso el arco para batir fibras. Los intentos de apropiación de su uso exclusivo por parte de los batidores de lana suabos no parece que tuvieran mucho éxito en el plano real, pero su asociación iconográfica al patrono tradicional del gremio, a Santiago el Menor, quizá se deba interpretar como otro medio de legitimación de su uso, en un plano divino, frente a los trabajadores de la nueva fibra textil: el algodón.

En este sentido, destaca la aparición más antigua del arco de batir en la portada de la torre de la iglesia parroquial de Ulm (actual catedral), el principal centro del Bachent y líder del Schwäbischer Städtebund, obra iniciada

108 Término italiano que hace referencia a los fabricantes de fustán (tejido de lino y algodón). En la manufactura del Bachent alemán se combinaba el algodón importado y el lino local que crecía en la zona de Suabia.

109 "Intense competition from German cities was the primary factor in the declinig fortunes of Italian cotton production" (M.F. Mazzaoui, The Italian, pp. 139-140).

${ }^{110}$ H. Rizzoli, Der Fachbogen, p. 52.

${ }_{111}$ H. Kellenbenz, The Fustian, pp. 261-262; M.F. Mazzaoui, The Italian, nota 10 y p. 194; R. Patterson, Spinning, p. 195, nota 8 (el entrecomillado es mío). 
por Ulrich von Ensingen en 1392. La portada de la torre es la única parte de la misma que quedó finalizada a la muerte del arquitecto en 1419 (fig. 7) ${ }^{112}$. La coincidencia de dos variantes iconográficas del atributo del apóstol en ese mismo edificio permitiría afinar en el establecimiento de la fecha del nacimiento de la nueva forma iconográfica, pues mientras que en los relieves de las arquivoltas del portal oeste, obra del maestro del Kreuzwinkel (ca. 14101417), aparece representado el martirio de Santiago el Menor de forma tradicional, siendo golpeado por un tosco madero en la cabeza, la escultura de la fachada del pórtico, atribuida al maestro Hartmann (ca. 1417-1422), sostiene con la mano izquierda el arco, constituido por una gruesa cuerda enrollada sobre sí misma (no se conserva la parte inferior del arco) ${ }^{113}$.

La aparición del arco en el otro gran centro algodonero alemán, Augsburgo, será algo más tardía y afectará no sólo a la iconografía del santo, sino también a la inclusión del arco en la heráldica. Así aparece en el altar de Kaiserheim, encargo del abad Georg II Kastner a tres artistas de la ciudad en 1502 (Holbein el Viejo, Adolf Kastner y Gregori), donde el comitente muestra su escudo de armas formado por un arco textil ${ }^{114}$. La expansión de la manufactura del algodón alemán, desde finales del siglo XIV o comienzos del XV, de Suabia a Renania, Austria, Bohemia, Silesia, Hungría y Polonia (en ese momento, Augsburgo ejerce de puente comercial entre las ciudades italianas y las hanseáticas $)^{115}$, igualmente parece anteceder la difusión de la representación iconográfica del apóstol y su nuevo atributo, pero parece que termina convirtiéndose en una simple particularidad de las regiones de habla alemana, ya sin fuerza revindicativa. La expansión de esta nueva iconografía debe mucho a las ediciones impresas en Suabia, como el Liber Chronicarum de Núremberg de Schedel de 1493 (fig. 12) ${ }^{116}$, y sobre todo a las xilografías que acompañan las diversas impresiones de la obra de Santiago de la Vorágine, en esa misma ciudad en $1472^{117}$. En los recuadros que ilustran la Legenda Aurea, Santiago el Menor comparte atributo con San Severo de Rávena, patrón de los tejedores $^{118}$. La popularidad de estas obras es la que explica la reproducción del apóstol con el arco en Biblias impresas en Amberes, a inicios del siglo

112 N. Nussbaum, German, pp. 146-147. Hay constancia de que en las obras participó el gremio de tejedores que, en 1385, financió varios vitrales de la parroquia.

113 G. Ringshausen, Die Archivoltenfiguren, pp. 209-241; R. Wortmann, Ulm, p. 12.

114 Pinakothek Münich no inv. 721-736 (W. D. Dube, The Munich, p. 85; G. Goldberg, Flügel, pp. 248-249).

${ }_{115}$ M.F. Mazzaoui, The Italian, p. 142. En el siglo XIV, se detecta un flujo de tejedores alemanes a las ciudades polacas (J. Wyrozumski, The Textile, p. 252).

116 Bayerische Staatsbibliothek Munchen, Núremberg no 1493.07.12, f.104v.

117 W.L. Strauss, The Illustrated, p. 65.

118 R P. Bedford, Saint James, p. 32; L. Réau, Iconographie, p. 703, nota 1 y pp. 1208-1209. 
XVI. Mientras que los ejemplos recopilados por Bedford en Polonia, como las esculturas de bronce de Santiago el Menor conservadas en las catedrales de Gniezno (1480) y Poznan (1498) ${ }^{119}$, o en Dinamarca, como las tallas de

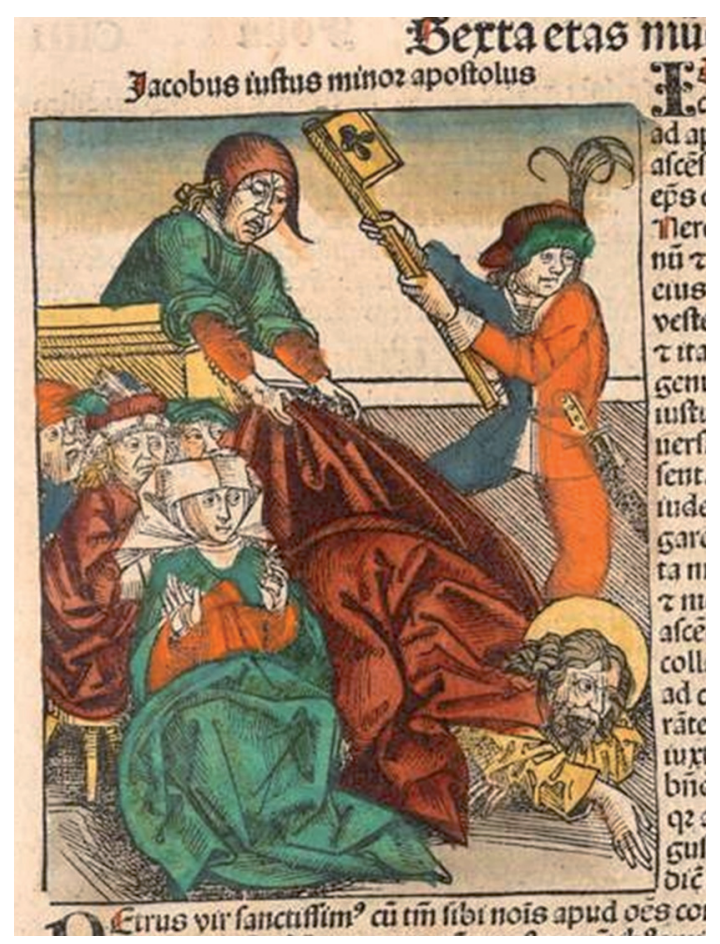

Fig. 12. Xilografía del martirio de Santiago el Menor en el Nuremberg Liber Chronicarum de H. Schedel. Ilustradores: M. Wolgemut y W. Pleydenwurff. Impresor: Anton Koberger. Núremberg, 1493.07.12. Libro impreso ilustrado con xilografías, 45,2x32,5 cm. Múnich, Bayerische Staatsbibliothek Munchen Sig. Rar. 287, f.104v.

madera policromada del retablo del altar mayor de la catedral de Aarhus de 1479 , son fruto de la circulación de obras y artesanos, pues en el último caso el autor del retablo es el alemán Bernt Notke ${ }^{120}$.

La presencia de esta variante iconográfica del arco fuera de la zona de influencia cultural alemana debe ser matizada. Bedford, en su extenso corpus, incluye una imagen en relieve de la arquivolta de la portada del transepto

119 R.P. Bedford, Saint James, pp. 31-32 y fig. 31-33

120 J. Roosval, Skulpturer, p. 325. Sobre la circulación de artistas en las regiones de habla alemana y zonas periféricas véase: N. Nussbaum, German, p. 142. 
norte de la catedral de Burdeos, que, tras un análisis minucioso, se revela como la clásica representación del apóstol con el bate, mientras que, un registro más arriba, la imagen del apóstol Felipe con una pequeña cruz en tau ha sido posiblemente la que provocó la confusión de este investigador inglés ${ }^{121}$. La otra pieza corresponde a un medallón esmaltado de Limoges, atribuido a Léonard Limousin ( $c a$. 1505-1575); por el contrario, en este caso, la identificación es incuestionable pues además del arco, el apóstol porta una leyenda en una filacteria (fig. 13) ${ }^{122}$, pero hay algo extraño en la ejecución del instrumento, pues éste no deja entrever el manto azul del santo, sino la total opacidad del hueco entre el palo y la cuerda del arco, como si éste fuera algo macizo (¿una sierra?). Este detalle permite constatar que, aunque el artista reprodujera un arco, no terminó de comprender lo que estaba representado, como si fuera ajeno a su acervo cultural o tecnológico.

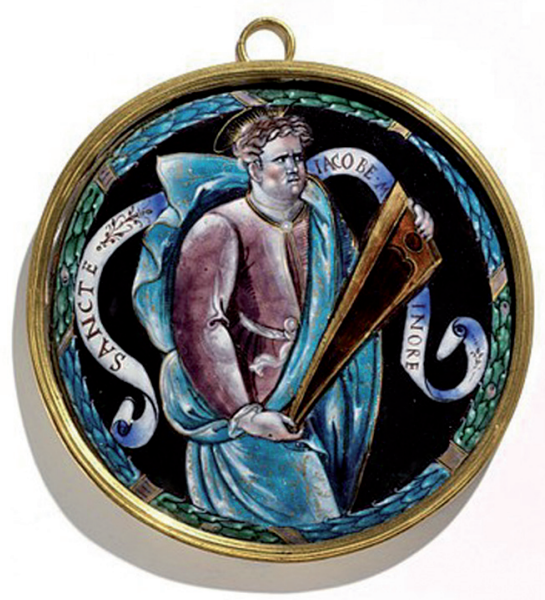

Fig. 13. Santiago el Menor con el arco. Medallón de Limoges del siglo XVI. Esmalte pintado y marco de cobre. Londres, Victoria and Albert Museum no inv. 228-1874.

El caso más curioso es el de la portada occidental de la catedral de Exeter (ca. 1375-1381), otro importante enclave textil de época medieval $^{123}$. El vínculo formal establecido entre las bóvedas estrelladas de las

121 R.P. Bedford, Saint James, p. 27; L. Réau, Iconographie, pp. 133 y 1068. Gardelles indica que la cruz de san Felipe está quebrada (J. Gardelles, La cathédral, p. 246). Quisiera agradecer el apoyo gráfico de D. Francisco de Asís García.

${ }_{122}$ Victoria and Albert Museum n ${ }^{\circ} 228-1874$ (R.P. Bedford, Saint James, p. 27 y fig. 24).

${ }^{123}$ En algún momento, el puerto de Exeter llegó a superar a Londres en el comercio de lana (A.R. Bridbury, Medieval, p. 83). 
naves laterales del transepto sur de este templo y las cubiertas de la iglesia cisterciense de Pelplin, en Prusia Occidental (posterior a 1276) ${ }^{124}$, no es suficiente para establecer también una conexión que explique, por derivación, el cambio de atributo del apóstol, pues éste figura en un añadido posterior a la catedral y recordemos que ningún ejemplo alemán es tan antiguo. El apóstol aparece en el rango superior de esculturas, completado por el obispo Brantyngham, sosteniendo dos atributos: la pertica y el arco (fig. 14) ${ }^{125}$. Esta duplicación de la simbología no puede tener más que una explicación que no descartaría un fenómeno de convergencia: el arco en Gran Bretaña es un hapax legomenon iconográfico que no acaba de vincularse inequívocamente con el apóstol, de ahí que se mantenga el atributo más tradicional, la pertica fullonis. A pesar de la voluntad del artista o del comitente por mantener la iconografía del santo inteligible para el observador, no puede evitar que se haya generado una confusión mayor de la habitual a la hora de identificar la figura (la segunda, comenzando por la derecha) pues, para algunos es Simón y, para otros, Tomás ${ }^{126}$. Incluso aunque se identifique correctamente con Santiago el Menor, el arco es confundido con una sierra. La aparición del arco en Gran Bretaña debe relacionarse con el batido de fibras cortas y la mezcla de lanas, puesto que el algodón, aunque importado en menor medida en los siglos XIII y XIV, no se usa en los tejidos ingleses hasta finales del siglo XVI ${ }^{127}$.

\section{EL NUEVO ATRIBUTO COMO GENERADOR DE CONFUSIÓN: LA SIERRA Y LA ESCUADRA}

El elemento identificador que surgió en el siglo XI como signo individualizador del colectivo de apóstoles, en la práctica, terminará resultando inadecuado. En la imagen de Santiago, se unen la aportación suaba y una confusión derivada de la incomprensión morfológica del arco textil, acrecentada, en el último siglo, por la total industrialización de la sociedad occidental. La causa no está clara, pero es un fenómeno constatado en otras regiones europeas, donde los tres hijos de María Cleofás (Santiago el Menor, Simón y Judas-Tadeo) suelen intercambiarse sus correspondientes emblemas, por lo que no es inhabitual asociar la sierra a Santiago y el bate a Simón o a Judas-Tadeo. El caos iden-

${ }^{124}$ N. Nussbaum, German, pp. 83-84.

${ }_{125}$ R.P. Bedford, Saint James, p. 27 y fig. 22; A. Gadner, English, pp. 220-221; fig. 432.

126 E. K. Prideaux, The Figure, p. 29 y lám. 20, C-21.

127 P. Walton, Textiles, pp. 322-323. Curiosamente, en este artículo no se hace ninguna referencia al arcado. 


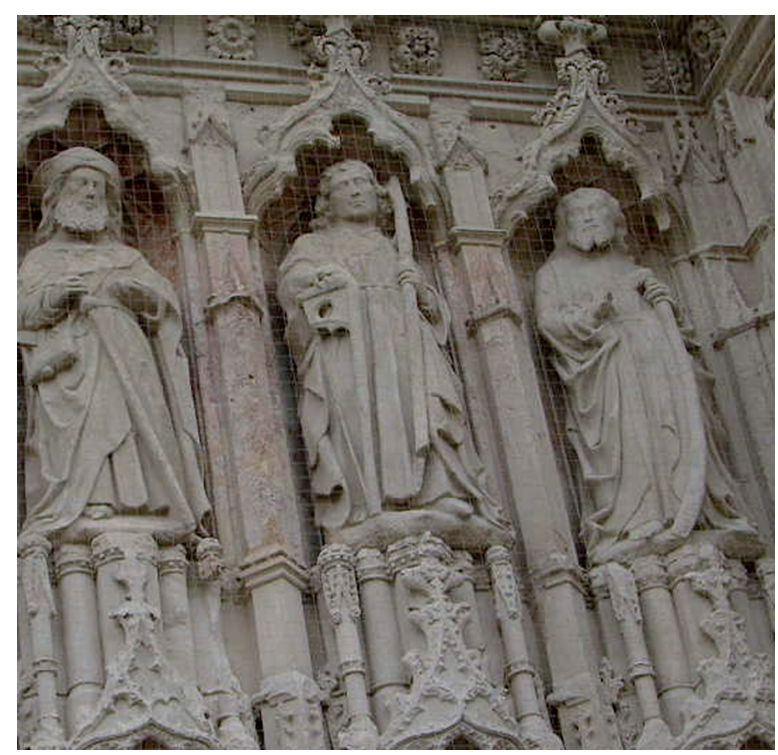

Fig. 14. Santiago el Menor con el arco y la pertica fullonis.

Escultura de la portada occidental de la catedral de Exeter, $c a$. 1375-1381.

tificativo provocado por la introducción del arco queda plasmado en la serie de grabados alemanes de los apóstoles de Schongauer ( $c a$. 1480), pues al carecer de nombres, da pie a las identificaciones divergentes de Hutchinson y Lehrs: el apóstol apoyado sobre el bate nudoso fue identificado con Judas-Tadeo y Santiago el Menor, respectivamente ${ }^{128}$. La misma apreciación se deriva de la serie de grabados de los apóstoles del maestro i-e (ca. 1480-1500) ${ }^{129}$. Sin embargo, a veces el error es más inexplicable pues la descripción del atributo se realiza de forma mecánica y contradice radicalmente el signo mostrado por la imagen ${ }^{130}$.

En el contexto anglosajón confluye otra circunstancia, pues es bastante corriente atribuir a Santiago el Menor la sierra como arma de martirio. Recordemos que Prideaux, a inicios del siglo XX, confundió el arco de la catedral de Exeter con una sierra, símbolo de Simón ${ }^{131}$. En Gran Bretaña, además

${ }^{128}$ I. Baum, Martin, fig. 56; J.C. Hutchison, The Illustrated, fig. 0.47 C2 (British Museum, Londres); M. Lehrs, Geschichte, vol. V, p. $223 \mathrm{n}^{\circ} 47$.

129 J.C. Hutchison, The Illustrated, pp. 297-299.

130 El grabado Cat. 10 de Basilea, el autor lo identifica con Santo Tomás with the fuller's $c l u b$, pero en la imagen lo que aparece representado es un arco (J. C. Hutchison, The Illustrated, p. 300).

${ }^{131}$ E.K. Prideaux, The Figure, p. 29; L. Réau, Iconographie, pp. 133 y 1224. 
de esa escultura monumental, debían circular pequeños objetos con la imagen de Santiago el Menor en su variante alemana, pero el número de ejemplares registrados no explica que sistemáticamente se asocie la sierra a Santiago, especialmente desde el siglo $\mathrm{XX}^{132}$. Podría ser una contaminatio nominis ${ }^{133} \mathrm{y}$ que el apóstol asuma, de forma espuria, la historia del desmembramiento de Santiago de Persia (Jacobus Intercissus) ${ }^{134}$.

En otras ocasiones, el empeño en identificar el arco de batir fibras en piezas artísticas ha dado pie a interpretaciones erróneas. La morfología de la llave de San Pedro puede generar esa confusión, eso explica que Bedford considerarse que la figura que aparece al lado de los apóstoles Tadeo y Matías del fresco tardogótico de la capilla del coro de la iglesia de Ottmarsheim era Santiago el Menor ( $c a .1460-1525)^{135}$. La similitud de ambos objetos es sorprendente, sin embargo, ese mismo objeto es el que entrega Cristo a Pedro en otro registro mural de esa misma iglesia, por lo que sólo puede ser la llave, una llave que carece de muescas como suele ser habitual. La escuadra de carpintero, asociada en ocasiones a Santiago el Menor, tampoco debe interpretarse como una versión reducida y mal entendida del arco, como sugiere Peter-Müller ${ }^{136}$, pues la escuadra de madera es símbolo del constructor y del carpintero y, aunque asociada principalmente a Tomás, por extensión puede vincularse a Judas-Tadeo o a Santiago el Menor ${ }^{137}$, como muestra el óleo sobre tabla de Rubens conservado en el Museo del Prado $(1610-1612)^{138}$.

${ }^{132}$ La creatividad hagiográfica no ha perdido ni un ápice de su vitalidad medieval e Internet se convierte en un muestrario muy original. Los ejemplos son numerosos en el ámbito anglosajón donde se llega a afirmar que después de ser arrojado del pináculo y apaleado, el cuerpo del apóstol fue aserrado. Incluso, para que el relato cobre verosimilitud se afirma que la fuente es el propio Hegesipo (http://old.allsaintspontiac.org/treasures/,

http://www.sundayeducation.com/2011/05/03/james-the-less-and-philip-mark-316-19daily-devotional/, consulta: 12/01/2012).

133 Esa misma explicación debe tener la adopción del gorro de peregrino por parte de Santiago el Menor, como se ve en el Libro de Angers (Bibliothèque National de France, Ms fr.10, f. $585 \mathrm{v})$.

134 Este personaje sufre martirio en 421 en Beth Lapat (Jorramabad, Irán) bajo Bahram V, pero el arma de martirio es un hacha y no una sierra (G. Balestri, H. Hyvernat, Acta; L. Réau, Iconographie, p. 704).

135 R. P. Bedford, Saint James, p. 28; J. Himmelspach, Ottmarsheim, pp. 12 y 17.

136 I. Peter-Müller, Sankt Jakob, p. 11.

137 C. Cahier, Caracteristiques, p. 376; L. Réau, Iconographie, p. 133.

${ }^{138}$ H. Vlieghe, Corpus, pp. 46 y 59; fig. 84 = Madrid, Museo del Prado, PO 1651. 


\section{UN EQUÍVOCO: EL JUEGO CONVERTIDO EN LABOR}

El último atributo asociado a Santiago el Menor es característico de una iconografía peculiar: la imagen de Santiago niño junto a su madre y hermanos en el icono conocido como la Santa Parentela o Linaje de Santa Ana. Lo normal es que los pequeños sostengan los atributos de su futuro martirio y así es en el caso de Santiago el Menor (bate o arco) ${ }^{139}$, salvo que también puede sostener un pequeño molinillo de viento - pintura del coro alto de la iglesia de St. Hellen de Ranworth, Norfolk (ca. 1430), tabla anónima del museo de Darmstadt (ca. 1430-1440) y una obra de un maestro tirolés conservado en el museo de Karlsruhe, $c a .1520$ (fig. 15) ${ }^{140}$. Bedford barajó la idea de que fuera una alusión a los batanes mecánicos, si bien éstos nunca fueron eólicos, sino hidráulicos. El molinillo tampoco parece que corresponda a una versión simplificada de la devanadera rotatoria, otro invento textil introducido en los siglos XI-XII ${ }^{141}$, pese a que es frecuente la imagen de niños ayudando a sus madres con las devanaderas, mientras éstas hilan ${ }^{142}$. No obstante, otras ilustraciones de la órbita alemana demuestran que es bastante usual esa representación infantil, que únicamente retrata juegos infantiles con molinillos y caballitos de juguete ${ }^{143}$.

\section{A MODO DE CONCLUSIÓN}

Las primeras imágenes del atributo del apóstol y su martirio son imágenes estereotipadas; no hay interés, por parte del artista, en ofrecer al espectador un retrato fidedigno del trabajo textil. La fidelidad al texto es algo secundario, pues prima el componente psicológico de la ejecución. No es necesario retratar una auténtica fustis o uectis fullonis, ya que no añade dramatismo a la narración.

139 R.P. Bedford, Saint James, pp. 27-28; D. Zinker, Masterpieces, pp. 130-133. R. Budde et al., Wallraf-Richartz, p. 35.

140 R.P. Bedford, Saint James, pp. 35-37 y fig. 38, 1-2 y 4.

${ }^{141}$ D. Cardon, La draperie, p. 284 y fig. 97.

142 En una Biblia Pauperum del segundo cuarto del siglo XV (Bayerische Staatsbibliothek de Munich, Cod. Lat. $28141 \mathrm{f}$. 4v), se ve al niño Jesús con una devanadera de aspas (D. Cardon, La draperie, p. 282, fig. 87 y 109).

${ }^{143}$ En el Splendor Solis, aparecen unos niños jugando con caballitos de juguete y molinillos idénticos a los de los cuadros alemanes de la Santa Parentela (British Library, Ms. Harley 3469, f. 31v). Otro ejemplo corresponde a una miniatura de las tres edades del hombre del Livre des propietés des choses de Bartolomé el inglés (siglo XIII), Poitiers, 1470-1490 (Bibliothèque National de France, Ms. fr. 218, f. 95r). Por tanto, tampoco parece verosímil que el caballito de juguete asociado a la figura de Santiago el Mayor sea una referencia al famoso caballo blanco de las batallas contra los musulmanes, como se ha afirmado en alguna ocasión (L. Réau, Iconographie, p. 143). 


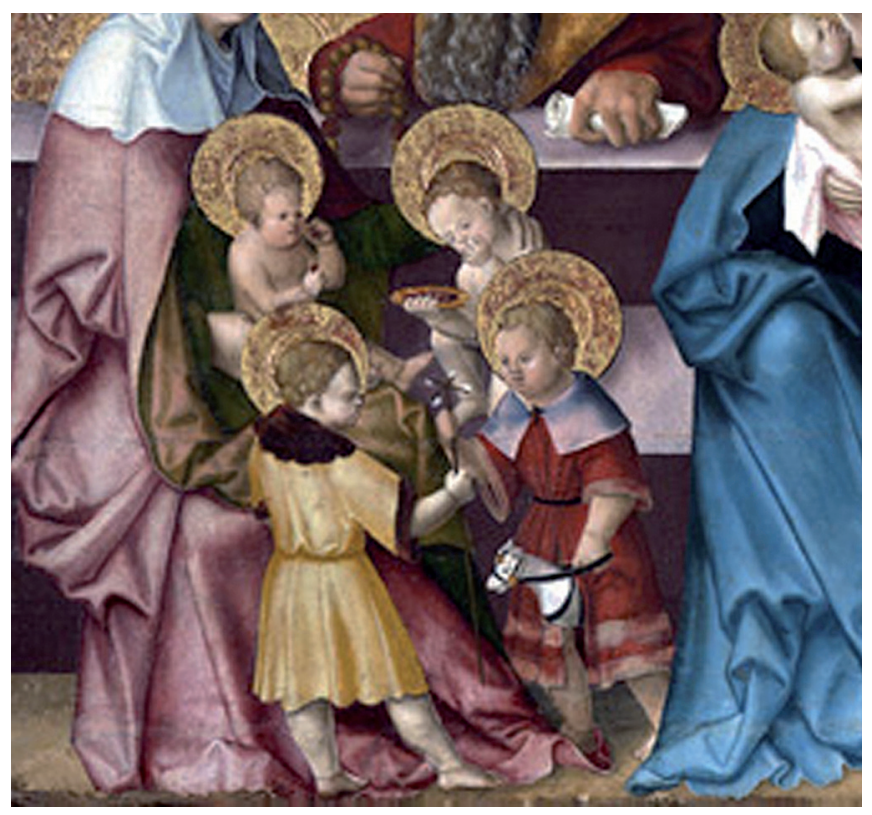

Fig. 15. Santiago el Menor niño con el molinillo de viento. Detalle del retablo de La Santa Parentela del Oberrheinischer Meister, 1520. Técnica mixta sobre tabla, 79x196 cm. Karlsruhe, Staatliche Kunsthalle ${ }^{\circ}$ inv. 74.

Desde el punto de vista lexicográfico, a finales del siglo VIII, se produce un cambio significativo en el relato latino con la introducción de la pertica fullonis; este cambio inesperado sólo se explica por una influencia directa y determinante del vocabulario propio de la actividad textil -no olvidemos que el ejecutor del apóstol pertenecía a este respetable oficio, uno de los que más ha aportado a la iconografía medieval, como fuente inagotable de recursos dramáticos, por el ejemplo, el martirio de San Blas. Así la pertica entra en escena, pero ésta es la herramienta de trabajo del cardador de paños o pelaire, no del fullo o pisador, y además aparece tardíamente, varios siglos más tarde a su incorporación al relato de la Passio Iacobi, pues los ejemplos iconográficos más antiguos son de finales del siglo XII o inicios del siguiente.

Por último, surge el arco de algodón o lana, un invento bien integrado en las principales corporaciones textiles europeas desde inicios del siglo XII, que se extendió gracias al crecimiento de la industria algodonera, aunque pronto fue adoptado para las lanas de fibra corta (siglo XIII). No obstante, no es hasta inicios del siglo XV cuando se produce la mutación iconográfica general y el arco pasa a sustituir a la pertica y al bate de bata- 
nero en la región alemana de Suabia, -la aparición del arco en Exeter debe considerarse un hallazgo aislado sin ninguna transcendencia en Gran Bretaña. Circunstancialmente, esa sustitución, que por otro lado no supone la eliminación de la iconografía tradicional del apóstol, coincide en el espacio y tiempo con una lucha de intereses económicos por el monopolio de la pujante industria del fustán alemán. Es difícil creer que ambos acontecimientos sean independientes y fruto de la casualidad. Lamentablemente, no es posible afirmar con rotundidad qué facción es la promotora del cambio iconográfico, aunque las reclamaciones de los batidores de lana que exigen el uso exclusivo del arco para su actividad frente a los batidores de algodón, inclinaría la balanza a su favor. Sean los batidores de lana o menos probablemente los arqueadores de algodón los responsables del cambio, lo cierto es que Santiago el Menor pronto adopta el arco en las principales ciudades suabas. En el transcurso del siglo XV, esta variante del atributo del apóstol perderá su matiz reivindicativo y comenzará a menudear en los países de habla alemana, prestándose a equívocos y creando leyendas y atributos espurios. Pese a que, en algún momento, se ha llamado la atención sobre la presencia del arco en los principales escudos de oficios textiles centroeuropeos, este tipo de emblema profesional otorga la misma relevancia a todas las herramientas del oficio -podaderas de tundidores, cardas de cardadores, mazos de enfurtir-; toda herramienta es digna de convertirse en signo porque cada una de ellas expresa la bondad y cumplimiento de las regulaciones de trabajo que realizan los distintos cuerpos de oficiales del gremio textil. En este mismo sentido, se debe interpretar los sellos de producción que emplean el arco como signo para individualizar producciones textiles (¿mezclas permitidas? ¿producciones individualizadas?) y, por tanto, nada tienen que ver con la iconografía del santo, salvo la coincidencia del instrumento de trabajo.

\section{BIBLIOGRAFÍA CITADA}

Allen, Michael I. (ed.), Frechulfi Lexoviensis. Historiarum libri XII, Turnhoult, Brepols, 2002. (CCCM; 169A).

Allsen, Thomas T., Commodity and Exchange in the Mongol Empire. A Cultural History of Islamic Textiles, Cambridge, Cambridge Studies in Islamic Civilization, 2002.

Anstruther, Robert (ed.), Radulfi Nigri Chronica, Londres, Caxton Society, 1855.

Bahat, Dan, Jerusalem, en Meyers, E.M. (ed.), The Oxford Encyclopedia of Archaeology in the Near East, 3, Oxford, Oxford University Press, 1997, pp. 224-238. 
Balestri, Giuseppe; Hyvernat, Henry (eds.), Acta Martyrum, Leuven, Universitatis Catholicae Americae-Universitatis Catholicae Lovaniensis, 1951-1955. (CSCO; 43-44).

Baum, Iulius, Martin Schongauer, Viena, Anton Schroll, 1949.

Bedford, Richard P., Saint James the Less. A Study of Christian Iconography, Londres, Publication of the Gryphon Club, 1911.

Bertoli, Bruno, I mosaici di San Marco. Iconografia dell'Antico e del Nuovo Testamento, Milán, Electa, 1986.

Biblioteca Vaticana, Il menologio di Basilio II (Cod. Vaticano Greco 1613), Turín, Fratelli Bocca, 1907.

BHL, Bibliotheca Hagiographica Latina Antiqua et Mediae Aetatis, Bruselas, Ed. Socii Bollandiani, 1898-1899, vol. I,

Blaise, Albert, Dictionnaire latin-français des auteurs chrétiens, Estrasburgo, Le Latin Chrétien, 1954.

Blánquez, Agustín, Diccionario latino-español, Barcelona, Editorial Sopena, 1988.

Blümner, Hugo, Technologie und Terminologie der Gewerbe und Künste bei Griechen und Römern, Leipzig, Georg Olms, 1912, vol. I.

Boeckler, Albert, Das Stuttgarter Passionale, Augsburgo, Filser, 1923.

Böhm, Barbara, Jakobus Minor, en W. Braunfels (ed.), Lexikon der Christlichen Ikonographie, Friburgo, Herder, 1974, vol. VII, cols. 47-51.

Bovon, François, Byzantine Witnesses for the Apocryphal Acts of the Apostles, en F. Bovon, A.G. Brock, C.R. Matthews (eds.), The Apocryphal Acts of the Apostles, Cambridge (Mass.), Harvard University Press, 1999, pp. 87-100.

Boyer, Blanche Beatrice; MacKeon, Richard Peter (eds.), Peter Abailard. Sic et Non: A Critical Edition, Chicago - Londres, The University of Chicago Press, 1976-1977.

Branchet, Auguste; Egger, Émile, Dictionnaire étymologique de la langue française, París, Bibliothèque d'Éducation, 1868.

Breton, Jean Baptiste, China: Its Costume, Arts and Manufactures, Londres, J. J. Stockdale, 1812.

Bridbury, Anthony R., Medieval English Clothmaking. An Economic Survey, Londres, Heinemann Educational Books, 1982.

Budde, Rainer; Czymmek, Götz; Lymant, Brigitte; Robels, Hella; Zehnder, Frank G., Wallraf-Richartz Museum Köln, Múnich, Magazin Press, 1987.

Cahier, Charles, Caractéristiques des saints dans l'art populaire, Bruselas, Librairie Poussielgue Frères, 1867.

Caillau, Armand Benjamin; Saint-Yves, B. (eds.), S. Aurelii Augustini Hipponensis episcopi operum supplementum, 2, París, Parent-Desbarres, 1836. 
Camesasca, Ettore, Mantegna, Madrid, Ed. Scale/Edibesa, 2002.

Cardon, Dominique, La draperie au moyen âge. Essor d'une grande industrie européenne, París, CNRS Éditions, 1999.

Carrère, Claude, Barcelone, centre économique à l'époque des difficultés, 1380-1462, París, Mouton, 1967.

Cartier, Michel, À propos de l'histoire du coton en Chine. Approche technologique, économique et sociale, "Études chinoises" 13 (1994), pp. 417-435.

Cartlidge, David R.; Elliot, James Keith, Art and the Christian Apocryphe, Londres, Routledge, 2001.

Chevalley, Denis Andre, Der Dom zu Augsburg. Die Kunstdenkmäler von Bayern, Múnich, R. Oldenbourg Verlag, 1995.

Córdoba de la Llave, Ricardo, La industria medieval de Córdoba, Córdoba, Obra cultural de la Caja Provincial de Ahorros de Córdoba, 1990.

Córdoba de la Llave, Ricardo, Los batanes hidráulicos de la Cuenca del Guadalquivir a fines de la Edad Media. Explotación y equipamento técnico, "Anuario de Estudios Medievales" 41/2 (2011), pp. 593-622.

Crawford, John Stephens, The Byzantine Shops at Sardis. Archaeological Exploration of Sardis, 9, Cambridge (Mass.), Harvard University Press, 1990.

Cross, James E., Cynewulf's Traditions about the Apostles in Fates of the Apostles, en Biddle, M.; Brown, J.; Clemoes, P. (eds.), Anglo-Saxon England, Cambridge, Cambridge University Press, 2007, pp. 163177.

Crowfoot, Elisabeth; Pritchard, Frances; Staniland, Kay, Textile and Clothing (1150-1450), Londres, Museum of London, 2001.

De Poerck, Guy, La draperie médievale en Flandre et en Artois. Technique et terminologie, Brujas, De Tempel, 1951.

De Sandoli, Sabino, Corpus Inscriptionum Crucesignatorum Terrae Sanctae (1099-1291). Testo, traduzione e annotazioni, Publication of the Studium Biblicum Franciscanum, 21, Jerusalén, Franciscan Printing Press, 1974.

De Santos, Aurelio, Later Acts of the Apostles, en Schneemelcher, W. (ed.), New Testament Apocrypha. II. Writtings Relating to the Apostles; Apocalypses and Related Subjects, Westminster, John Knox Press, 1992, pp. 426-482.

Demus, Otto, The Mosaic Decoration of San Marco, Venice, Chicago, University of Chicago Press, 1988.

DeVries, Kelly, Medieval Military Technology, Toronto, University of Toronto, 1992.

Diccionario de Autoridades (1726-1737), Real Academia Española, Madrid, Editorial Gredos, 1969. 
Diderot, Denis; D’Alembert, Jean le Rond (eds.), Encyclopédie ou dictionnaire raisonné des sciences, des arts et des métiers, París, Briasson, 1751-1780.

Du Cange, Charles du Fresne (Monsieur), Glossarium mediae et infimae latinitatis, París, Librairie des sciences et des arts, 1938.

Dube, Wolf-Dieter, The Munich Gallery. Alte Pinakothek, Londres, Thames \& Hudson, 1970.

Dümmler, Ernest (ed.), Carmina Cenomanensia, MGH, Poetae Latini Medii Aeui, 2, Berlín, Weidmannschen Verlagsbuchhandlung, 1884.

Ernout, Alfred; Meillet, Antoine, Dictionnaire étymologique de la langue latine. Histoire des mots, París, Klincksieck, 1967.

Fagniez, Gustave, Études sur l'industrie et la classe industrielle à Paris au XIIIe et au XIVe siècle, París, Bibliothèque de l'École des Hautes Études, 1877.

Feldhaus, Franz Maria, Die Technik der Antike und des Mittelalters, Hildesheim, Georg Olms, 1985.

Feldman, Louis H. (ed.), Josephus. Jewish Antiquities, Books XVIII-XX, Londres, The Loeb Classical Library - Cambridge (Mass.), Harvard University Press, 1965.

Flachat, Jean Claude, Observations sur le commerce et les arts d'une partie de l'Europe, de l'Asie, Lyon, Jacquenod et Rusand, 1766.

Flury, Peter; Hillen, Michael; Holmes, Nigel (eds.), Pertica, en Thesaurus Linguae Latinae, Leipzig-Múnich, Teubner, 2000, Vol. X-2, fasc. 12, cols. 1784-1786.

Forbes, Robert James, Studies in Ancient Technology, Leiden, Brill, 1964, vol. IV.

Gadner, Arthur, English Medieval Sculpture, Cambridge, Cambridge University Press, 2011.

García Iglesias, José Manuel, Santiagos de Santiago. Dos apóstoles al final del camino, Santiago de Compostela, Alvarellos editora, 2011.

Gardelles, Jacques, La cathédrale Saint André de Bordeaux: sa place dans l'évolution de l'architecture et de la sculpture, Burdeos, Librairie Delmas, 1963.

Gardiner, E. Norman, Further Notes on the Greek Jump, "The Journal of Hellenic Studies" 24 (1904), pp. 179-194.

Glare, P. G. W. (ed.), Oxford Latin Dictionary, Oxford, The Clarendon Press, 1982.

Goetz, Georg, Corpus glossariorum Latinorum, Amsterdam, A.M. Hakkert, 1965 , vol. VII.

Goldberg, Gisela, Flügel des Kaisheimer Altars, en Alte Pinakothek München. Erläuterungen zu den ausgestellten Gemälden, Múnich, Bayerische Staatgemäldesammlungen, 1983, pp. 248-250. 
Götz, Georg Polycarpius (ed.), Liber Quare, Turnhoult, Brepols, 1983. (CCCM; 60).

Graesse, Theodor (ed.), Iacobi a Voragine Legenda Aurea uulgo Historia Lombardica dicta, Leipzig, Librariae Arnoldianae, 1850.

Grape, Wolfgang, The Bayeux Tapestry. Monument to a Norman Triumph, Nueva York, Prestel, 1994.

Grenser, Alfred, Zunft-Wappen und Handwerker-Insignien: eine Heraldik der Künste und Gewerbe, Frankfurt, Keller, 1889.

Grimm, Jacob; Grimm, Wilhelm (eds.), Deutsches Wörterbuch, Leipzig, Hirrel, 1913, vol. XIV-2.

Ha-Kohen, Israel Meir (ed.), Mishnah Berurah: the Classical Commentary to Shulchan Aruch Orach Comprising the Laws of Daily Jewish Conduct, Jerusalén, Pisgah Foundation, 1980.

Halkin, François, Auctarium Bibliothecae Hagiographicae Graeca, Bruselas, Soc. des Bollandistes, 1969, (Subsidia Hagiographica; 45).

Halkin, François, Nouum auctarium. Bibliotheca Hagiographica Graeca, Bruselas, Soc. des Bollandistes, 1984, (Subsidia Hagiographica; 47).

Harris, Henry T., Monograph on the Carpet Weaving Industry of Southern India, Madras, Madras Government Press, 1908.

Hartmann, Paul, Die gotische Monumental-Plastik in Schwaben, Múnich, F. Bruckmann, 1910.

Hilaire-Pérez, Liliane, Cultures techniques et pratiques de l'échange, entre Lyon et le Levant: inventions et réseaux aux XVIIIè siècles, "Belin" 49/1 (2002), pp. 89-114.

Himmelspach, Julien, Ottmarsheim. Zentralbau des 11.Jh, Lyon, Guillet-Lescuyer, 1986.

Hoffmann, Marta, The Warp-Weighted Loom. Studies in the History and Technology of an Ancient Implement, Studia Norvegica, 14, Oslo, Universitetsforlaget, 1964.

Holder-Egger, Oswald (ed.), Chronica minor auctore minorita Erphordensis. Monumenta Erphesfurtensia, MGH Scriptores Rerum Germanicarum, 42, Hannover - Leipzig, Impensis bibliopolii Hahniani, 1899.

Hutchison, Jane Campbell, The Illustrated Bartsch. vol. VIII: Commentary Part 1. Early German Artists. Martin Schongauer, Ludwig Schongauer, and Copyist, Nueva York, Abaris Books, 1996.

Huygens, Robert B. C. (ed.), Peregrinationes tres: Saewulf, John of Würzburg. Theodericus. Turnhoult, Brepols, 1994. (CCCM; 139).

Iradiel, Paulino, Evolución de la industria textil castellana en los siglos XIIIXVI. Factores de desarrollo, organización y costes de la producción manufacturera en Cuenca, Salamanca, Universidad de Salamanca, 1974. (Acta Salmanticensia, 84). 
Kaftal, Georg, Iconography of the Saints in Central and South Italian Painting, Florencia, Sansoni, 1965.

Kellenbenz, Hermann, The Fustian Industry of the Ulm Region in the Fifteenth and Early Sixteenth Centuries, en Harte, N.B.; Ponting, K.G. (eds.), Cloth and Clothing in Medieval Europe. Essays in Memory of Professor E. M. Carus-Wilson, Londres, Heinemann Educational, 1983, pp. 259-278.

Kiesow, Gottfried, Sankt Marien in Wismar. Geschichte eines Kirchenbaus, Bauten der Macht. Eine Kirchenbaustelle im Mittelalter, Bonn, Monumente Publikationen, 2002.

Klober, Friedrich, Baugeschichte des Ostchores. Kunsthistorische Beurteilung der Portalskulpturen, en Das Südportal des Augsburger Domes Geschichte und Konservierung, Arbeitshefte des Bayerischen Landesamtes für Denkmalpflege, 23, Múnich, Bayerisches Landesamt für Denkmalpflege, 1984, pp. 7-29.

Krusch, Bruno (ed.), Gregorius Turonensis. Liber in gloria martyrum, MGH Scriptores Rerum Merouingicarum, 1-2, Hannover, Impensis bibliopolii Hahniani, 1885.

Lacarra, María del Carmen, La influencia de los pintores italianos en los talleres aragoneses durante el siglo XIV, en Homenaje a D. Federico Balaguer Sánchez, Huesca, Instituto de Estudios Altoaragoneses, 1987, pp. 425-447.

Larsow, Ferdinand; Parthey, Gustav (eds.), Eusebii Pamphili Episcopi Caesariensis Onomasticon. Vrbium et locorum sacrae scripturae. Graece cum latina Hieronymi Interpretatione, Berlín, F. Nicolai, 1862.

Laufer, Berthold, The Early History of Felt, "American Anthropologist" 32/1 (1930), pp. 1-18.

Laughlin, John C. H, Archaeology and the Bible, Londres - Nueva York, Routledge, 2000.

Leclerq, Henri, Jacques le mineur, en F. Cabrol; H. Leclerq (eds.), Dictionaire d'archéologie chrétienne et de liturgie, París, Libraire Latouzey et Ané, 1927, vol. VII-2, cols. 2109-2116.

Lehrs, Max, Geschichte und kritischer katalog des deutschen niederländischen und französischen kupferstichs im XV. Jahrundert, Viena, Gesellschaft für Vervielfältigende Kunst, 1908-1934.

Leloir, Louis, Écrits apocryphes sur les apôtres. Traduction de l'édition arménienne de Venise, II, Turnhout, Brepols, 1992. (CC Series Apocryphorum).

Lewis, Charlton T., A Latin Dictionary, Oxford, Oxford University Press, 1870.

Liddell, Henry George; Scott, Robert, A Greek-English Lexicon, Oxford, The Clarendon Press, 1968. 
Lindsay, Wallace Martin (ed.), Isidori Hispaliensis Episcopi Etymologiarum siue Originum Libri XX, Oxford, The Clarendon Press, 1911. (Scriptorum Classicorum Bibliotheca Oxoniensis).

Lindsay, Wallace Martin (ed.), T. Macci Plauti Comoediae, vol. I, Oxford, The Clarendon Press, 1968.

Mâle, Émile, Notre-Dame de Chartres, París, Paul Hertman, 1948.

Mazar, Benjamin, The Archaeological Excavations near the Temple Mount, en Yadin, Y. (ed.), Jerusalem Revealed: Archaeology in the Holy City, 1968-1974, Jerusalén, Israel Exploration Society, 1975, pp. 25-40.

Mazzaoui, Maureen Fennell, The Italian Cotton Industry in the Later Middle Ages, 1100-1600, Cambridge, Cambridge University Press, 1981.

Mazzarino, Antonio (ed.), M. Porci Catonis De agricultura, Stuttgart, Teubner, 1982. (Bibliotheca Scriptorum Graecorum et Romanorum Teubneriana).

McCulloh, John (ed.), Rabani Mauri Martyrologium, Turnholt, Brepols, 1978. (CCCM; 44).

Migne, Jacques Paul (ed.), Ieronimus. De uiris illustribus liber ad dextrum, París, Vrayet, 1845. (PL; 23).

Migne, Jacques Paul (ed.), Joannes Wirzburgensis Presbyterus Descriptio Terra Sanctae, París, [s.n.], 1854. (PL; 155)

Migne, Jacques Paul (ed.), Opera Theologica Peregrinorum Aetatis Patristicae. Libri de ortu et obitu patriarcharum editio Patrologiae, París, [s.n.], 1850. (PL; 83)

Moeller, Walter O., The Wool Trade of Ancient Pompeii, Studies of the Ducht Archaeological and Historical Society, Leiden, Brill, 1976.

Mommsen, Theodor (ed.), Gildas. De excidio Britanniae, MGH Auctores Antiquissimi, 13, Berlín, [s.n.], 1896.

Munro, John Henry, Medieval Woollens: Textiles, Textile Technology and Industrial Organisation, ca. 800-1500, en Jenkins, D. (ed.), The Cambridge History of Western Textiles, Cambridge, Cambridge University Press, 2003, vol. I, pp. 181-227.

Munro, John Henry, Textiles, en Mantello, F.A.C.; Rigg, A.G. (eds.), Medieval Latin. An Introduction and Bibliographical Guide, Washington, The Catholic University of America Press, 1996, pp. 474-484.

Munro, John Henry, Wool and Wool-Based Textiles in the West European Economy, ca. 800-1500: Innovations and Traditions in Textile Products, Technology, and Industrial Organisation, en Working Papers, University of Toronto, 2000. http://repec. economics.utoronto.ca/files/UT-ECIPA-MUNRO-00-05.pdf, [consulta: 12/01/2012]. 
Nieto, Lidio; Alvar, Manuel, Nuevo tesoro lexicográfico del español (siglo XIV-1726), Madrid, Arco Libros, 2007.

Nussbaum, Norbert, German Gothic Church Architecture, New Haven, Yale University Press, 2000.

Patterson, R., Spinning and Weaving, en Singer, C.; Holmyard, E.J.; Hall A.R.; Williams, T.I. (eds.), A History of Technology, Oxford, The Clarendon Press, 1957, vol. II, pp. 191-220.

Peter-Müller, Irmgard, Sankt Jakob mit dem Wollbogen, "Keramikfreunde der Schweiz" 87 (1975), pp. 9-11.

Plotino, Roberto, Giacomo il minore, en Bibliotheca Sanctorum, Roma, Pontificia Università Lateranense, 1965, vol. VI, cols. 401-411.

Pociña, Andrés, Recursos dramáticos primordiales en la comedia popular latina, "Cuadernos de Filología Clásica" 8 (1975), pp. 239-275.

Prideaux, Edith K., The Figure Sculpture of the West Front of Exeter Cathedral Church: A Complete Photographic Record with Notes, Exeter, J. G. Commin, 1912.

Pringle, Denys, The Churches of the Crusader Kingdom of Jerusalem: a Corpus. Vol. III: The City of Jerusalem, Cambridge, Cambridge University Press, 2007.

Quadri, Riccardo (ed.), Heirici Autissiodorensis Homiliae per circulum anni, Turnhoult, Brepols, 1992-1994. (CCCM; 116).

RAE, Diccionario de la lengua española, Madrid, Espasa Calpe, 1992.

Réau, Louis, Iconographie de l'art chrétien. París, Presses Universitaires de France, 1958.

Rettich, Edeltraud, Meister des Oberaltaicher Schmerzenmannes, en Alte Meister. Staatsgalerie Stuttgart, Stuttgart, Staatsgalerie, 1992, pp. 240-241.

Ribbert, Margret, Die Kunstsammlung des Vereins, en Der Geschichte treuer Hüter .... Die Sammlungen des Vereins für Kunst and Altertum in Ulm und Oberschwaben. Ulmer Museum, Ulm, Süddeutsche Verlagsgesellschaft, 1991, pp. 10-58.

Ricci, Elisa, Mille santi nell'arte, Milán, Ulrico Hoepli, 1931.

Ringshausen, Gerhard, Die Archivoltenfiguren des Ulmer Westportales, en Specker, E.; Wortmann, R. (eds.), 600 Jahre Ulmer Münster, Ulm, Festschrift Ulm, 1977, pp. 209-241.

Rizzoli, Helmut, Der Fachbogen der Hut-und Tuchmacher als Spätmittelalterliches Heiligenattribut in Tirol, "Monatszeitschrift für Südtiroler Landeskunde" 60 (1986), pp. 52-60.

Roch, Jean-Louis, Innovations et résistances dans la draperie: exemples normands, "Médiévales" 39 (2000), pp. 46-56.

Roosval, Johnny, Skulpturer af Bernt Notke Från Köpings kyrka på Öland, "Fornvännen” 21 (1936), pp. 321-326. 
Sampaolo, Valeria, Fullonica, en Pugliese Carratelli, G., Pompeii. Pitture e mosaici, vol. IV, Regio VI, parte prima, Roma, Istituto della Enciclopedia Italiana, 1993, pp. 604-610.

Sampaolo, Valeria, Officina coactiliaria di Verecundus, en Pugliese Carratelli, G., Pompeii. Pitture e mosaici, vol. IX, Roma, Istituto della Enciclopedia Italiana, 1999, pp. 774-778.

Sánchez Cantón, Francisco Javier (ed.), Francisco Pacheco. Arte de la pintura, edición del manuscrito original, acabado el 24 de enero de 1638, Tomo II, Madrid, [s.n.], 1956.

Sánchez Ladero, Lázaro, Oficios. Vida y costumbres de la Edad Media, Barcelona, Editorial Sopena, 1982.

Schlie, Friedrich, Die Kunst und Geschichts-Denkmäler des Grossherzogthums Meclenburg-Schwerin, Leipzig, Bärensprungschen Hofbuchdruckerei, 1889-1899. Vols. II-III.

Schwartz, Eduard; Mommsen, Theodor (eds.), Eusebius Werke. Die Kirchengeschichte, Berlín, Akademie Verlag, 1992, Vol. V-2.1.

Simpson, John A.; Weiner, Edmund S. C. (eds.), The Oxford English Dictionary, Oxford, The Clarendon Press, 1989.

Strauss, Walter L., The Illustrated Bartsch German Book vol. X: Sixteenth Century German Artists. Albretch Dürer, Nueva York, Abaris Books, 1981.

The National Gallery, Late Gothic Art from Cologne, Londres, The National Gallery, 1977.

TLF, Trésor de la langue française. Dictionnaire de la langue du XIXe et du XXe (1789-1960), París, CNRS, 1971-1994.

Turnau, Irena, Hand-Felting in Europe and Asia. From the Middle Ages to the 20th Century. Institute of Archaeology and Ethnology, Varsovia, Polish Academy of Sciencies, 1997.

Uscatescu, Alexandra, En torno a la tendicula de Séneca (Quaest. Nat., 1,3,2): Una aproximación léxica e iconográfica a la ars fullonia, "Archivo Español de Arqueología" 83 (2010), pp. 203-220.

Uscatescu, Alexandra, Fullonicae y Tinctoriae en el Mundo Romano, Barcelona, Universitat de Barcelona, 1994. (Col-lecció Cornucopia; 1. Repertoris i materials per a l'estudi del Món Clàssic).

Vlieghe, Hans, Corpus Rubenianum Ludwig Burchard. Saints, Bruselas, Ed. Arcade, 1972, Vol. VII-1.

Von Stokar, Walter, Spinnen und Weben bei den Germanen. Mannus. Zeitschrift für Deutsche Vorgeschichte, 59, Leipzig, Curt Kabitzsch Verlag, 1938.

Walton, Penelope, Textiles, en Blair, J.; Ramsey, N. (eds.), English Medieval Industries, Cambridge, Cambridge University Press, 2001, pp. 319354. 
Weiland, Ludwig (ed.), Martini Oppaviensis. Chronicon pontificum et imperatorum, Berlín, Hieremann, 1872. (MGH Scriptores; 22).

Wild, John Peter, Textile Manufacture in the Northern Roman Provinces, Cambridge, Cambridge Classical Studies, 1970.

Wisti Lassen, Agnete, Tools, Procedures and Professions: A Review of the Akkadian Textile Terminology, en Michel, C.; Nosch, M.L. (eds.), Textile Terminologies in the Ancient Near East and Mediterranean from the Third to the First Millennia BC. Oxford, Oxbow Books, 2010, pp. 270-280. (Ancient Textile Series; 8).

Wortmann, Reinhard, Ulm Minster, Múnich, DKV Art Guide, 2010.

Wyrozumski, Jerzy, The Textile Trade of Poland in the Middle Ages, en Harte, N.B.; Ponting, K.G. (eds.), Cloth and Clothing in Medieval Europe. Essays in Memory of Professor E. M. Carus-Wilson, Londres, Heinemann Educational, 1983, pp. 248-258.

Zimmermann, Harald (ed.), Thomas Ebendorfer. Chronica regum Romanorum, MGH Scriptores rerum Germanicarum, Hannover, Hahnsche Buchhandlung, 2003. (Nova series; 18).

Zinker, Detler, Masterpieces from the Middle Ages to the Barroque at the Augustiner-Museum in Freiburg im Breisgau, Berlín - Múnich, Deutscher Kunsverlag, 2010.

Fecha de recepción del artículo: mayo 2012

Fecha de aceptación y versión final: septiembre 2012 